\title{
التوزيع الجغرافي لزراعة وإنتاج محاصيل الخضر الصيفية في قضاء عفك لعام 2019
}

\author{
أ. م. د. انتظار إبراهيم الموسوي \\ 07813133500: الموبايل \\ hussien@qu.edu.iq : الايميل

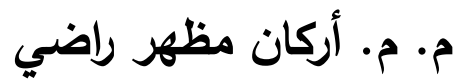 \\ كلية الآداب / جامعة القادسية
}

الملخص:

يدرس البحث التوزيع الجغرافي لزراعة الخضر الصيفية في قضاء عفك لمعرفة أهم العوامل الجغرافية المؤثرة على ذلك التوزيع ودرجة التباين في المساحات المزروعة بحسب المقاطعات الزراعية وكمية الانتاج والانتاجية للدحاصيل. وقد توصل البحث الى استتاجات علمية كان من أهمها إن نسبة (72,4\%) من

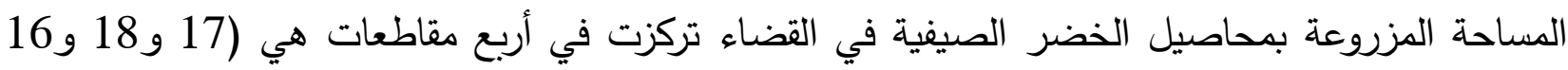
و24) وبنسبة (27,3\% و17,9\% و 15,1\% و 12,1\%) لكلٍ منها على الترتيب ، بينما لم تزرع هذه فئه المحاصيل في مقاطعتي (26 و 21) الأولى لثحة المياه والثانية لصغر مساحتها وتخصصها بزراعة بساتين

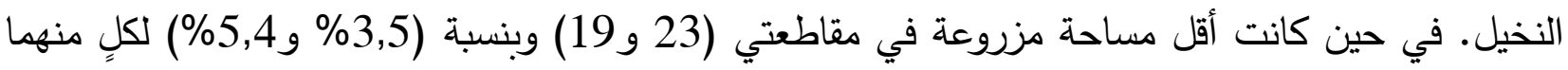
على الترتيب. وإن أكبر كمية إنتاج تحققت في محصولي الرقي والبطيخ بينما تحقق أقل كمية إنتاج في

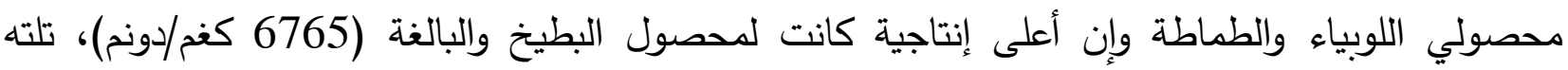

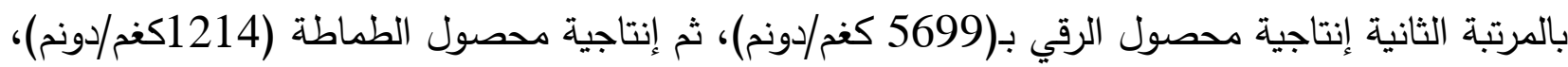

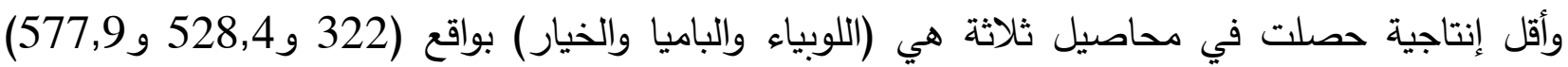

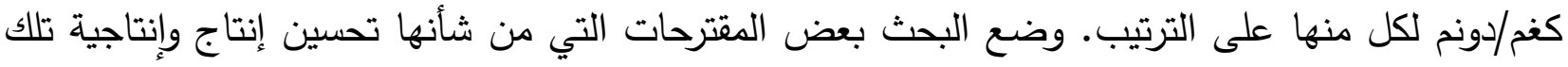
المحاصيل لسد الحاجة المحلية والاقليمية منها مثل توفير الدعم الحكومي وتوفير القروض الزراعية للمزارعين

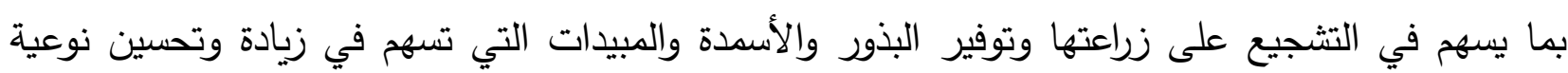
المنتج وزيادته. واخيراً توعية الفلاحين من قبل المرشدين الزراعيين على أهمية زراعة تلك المحاصيل وتيل ليساهم بزيادة جودة المنتج الزراعي المحلي. الكلمات المفتاحية : التوزيع الجغرافي ، إنتاج المحاصيل ، الخضر الصيفية ، قضاء عفك . 
مجلة أبحاث ميسان ، المجلد السادس عشر، العدد الثاني والثلاثون ، كانون الأول، السنة

The geographical distribution of the cultivation and production of summer vegetable crops in Afak district for the year 2019

\author{
Dr. Intidar Ibrahim Hussien Al_Musawy \\ Mobile: 07813133500 \\ Email: hussien@qu.edu.iq \\ Assistant Lecturer. arkan mazhar rady \\ College of Arts / University of Al-Qadisyia
}

\begin{abstract}
:
The research studies the geographical distribution of summer vegetable cultivation in Afak district to find out the most important geographical factors affecting that distribution and the degree of variation in the cultivated areas according to the agricultural provinces and the amount of their production and productivity. The research reached scientific conclusions, the most important of which was that $(72.4 \%)$ of the area planted with summer vegetable crops in district was concentrated in four provinces $(17,18,16$ and 24$)$ and by $(27.3 \%$, $17.9 \%, 15.1 \%$ and $12.1 \%$ ). While the lowest cultivated area was in the provinces (23 and 19$)$ and by (3.5\% and 5.4\%) each, respectively. The largest production was achieved in the crops of watermelon and watermelon, while the smallest amount of production was achieved in the beans and tomato crops. The highest productivity was for watermelon crop $(6765 \mathrm{~kg} /$ dunum), followed by the second highest yield of grazing crop (5699 $\mathrm{kg} / \mathrm{dunum})$, then tomato crop yield (1214 $\mathrm{kg} /$ dunum), and the lowest productivity was in three crops (cowpea, okra, and cucumber) According to $(322,528.4$ and 577.9) k/dunum each, respectively. The research forward some proposals that improve the production and productivity of these crops to meet the local and regional needs, such as providing government support and providing agricultural loans to farmers, which contributes to
\end{abstract}


مجلة أبحاث ميسان ، المجلد السادس عشر، العدد الثاني والثلاثون ، كانون الأول، السنة

encouraging their cultivation and providing seeds, fertilizers and pesticides that contribute to increasing and improving the quality and increase of the product. Finally, farmers are educated by the agricultural extension agents on the importance of cultivating these crops to contribute to increasing the quality of the local agricultural product.

Key words: geographical distribution, crop production, summer vegetables, Afak district.

أن الجغرافية علم مكاني يدرس تباين الظواهر الجغرافية ويوضح العلاقات السببية لتغيرات خصائص

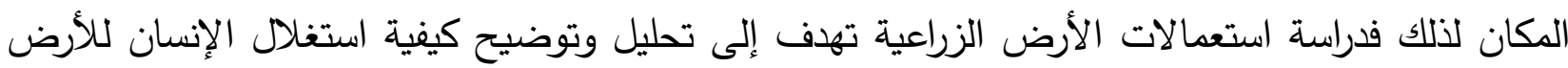
وإظهار مستوى استثماره لها في نطاق معين من خلال مدة زمنية محددة لمعرفة مدى التوافق بين الإمكانات الجغرافية المتاحة من ناحية والاستعمال من حيث مستواه وحجمه ونوعيته وخصائص أدوات الإنتاج المختلفة ومدى كفايتها من ناحية اخرى.

1. مشكلة البحث: ويمكن صياغة بالتساؤل الرئيس الآتي (ما هو التوزيع الجغرافي لمحاصيل الخضر

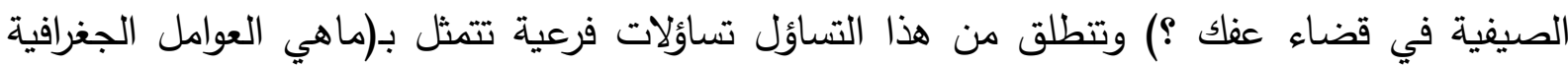

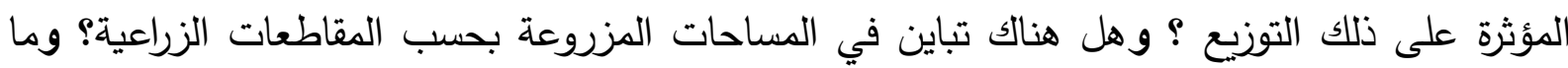

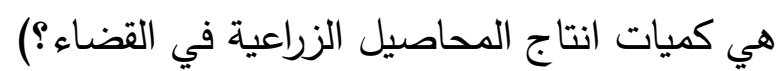
2. فرضية البحث: تتمثل فرضية البحث الرئيسة با(تتوزع زراعة محاصيل الخضر الصيفية في معظم

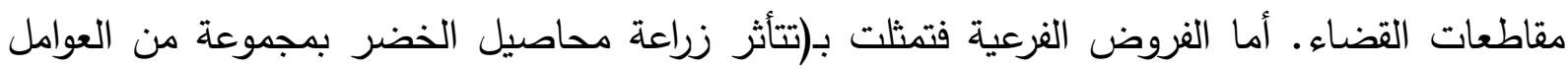
الطبيعية والبشرية. وتتباين المساحات المزروعة من مقاطعة إلى أخرى. وهنالك تباين في كميات الإنتاج والإنتاجية لتلك المحاصيل) 3. هدف البحث ومبرراته : يهدف البحث إلى الوقوف على واقع حال التوزيع الجغرافي للمساحات المزروعة

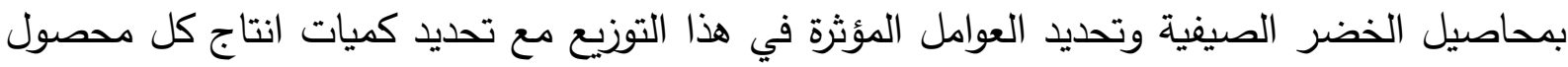

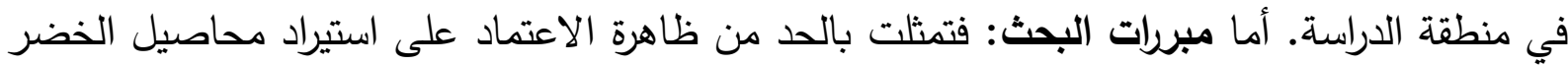

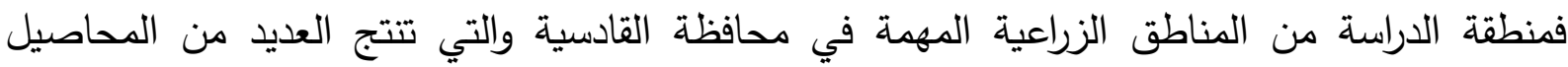

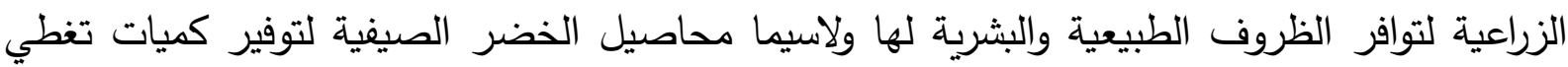
حاجة المحافظة منها وتصدير قسم منها إلى الدحافظات المجاورة. 
مجلة أبحاث ميسان ، المجلد السادس عشر، العدد الثاني والثلاثون ، كانون الأول، السنة 2020

4. منهج البحث: بالمنهجين النظامي والتحليلي لدراسة وتحديد العوامل الجغرافية المؤثرة في التوزيع الجغرافي لزراعة محاصيل الخضر وتحليل هذا التوزيع بحسب المقاطعات الزراعية. 5. حدود البحث: فتمثلت بالحدود الزمانية للموسم الصيفي في عام 2019. أما الحدود المكانية فيقع القضاء

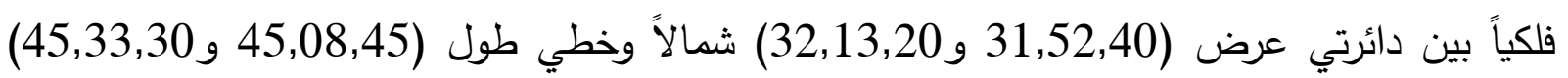
شرقاً ، ويحده من الثمال والثمال الغربي ناحية نفر ومن الغرب قضاء الديوانية ومن الثرق محافظة

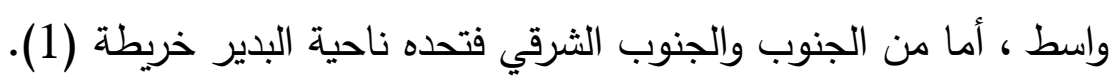

6. هيكلية البحث: مقدمة ومبحثين تتاول المبحث الأول (العوامل الجغرافية المؤثرة في زراعة محاصيل البحنيل

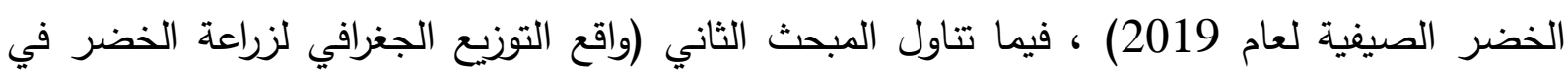

قضاء عفاك)، بالإضافة إلى الاستتتاجات والمقترحات وقائمة بالهوامش والمصادر . خريطة (1) وقع منطقة الدراسة

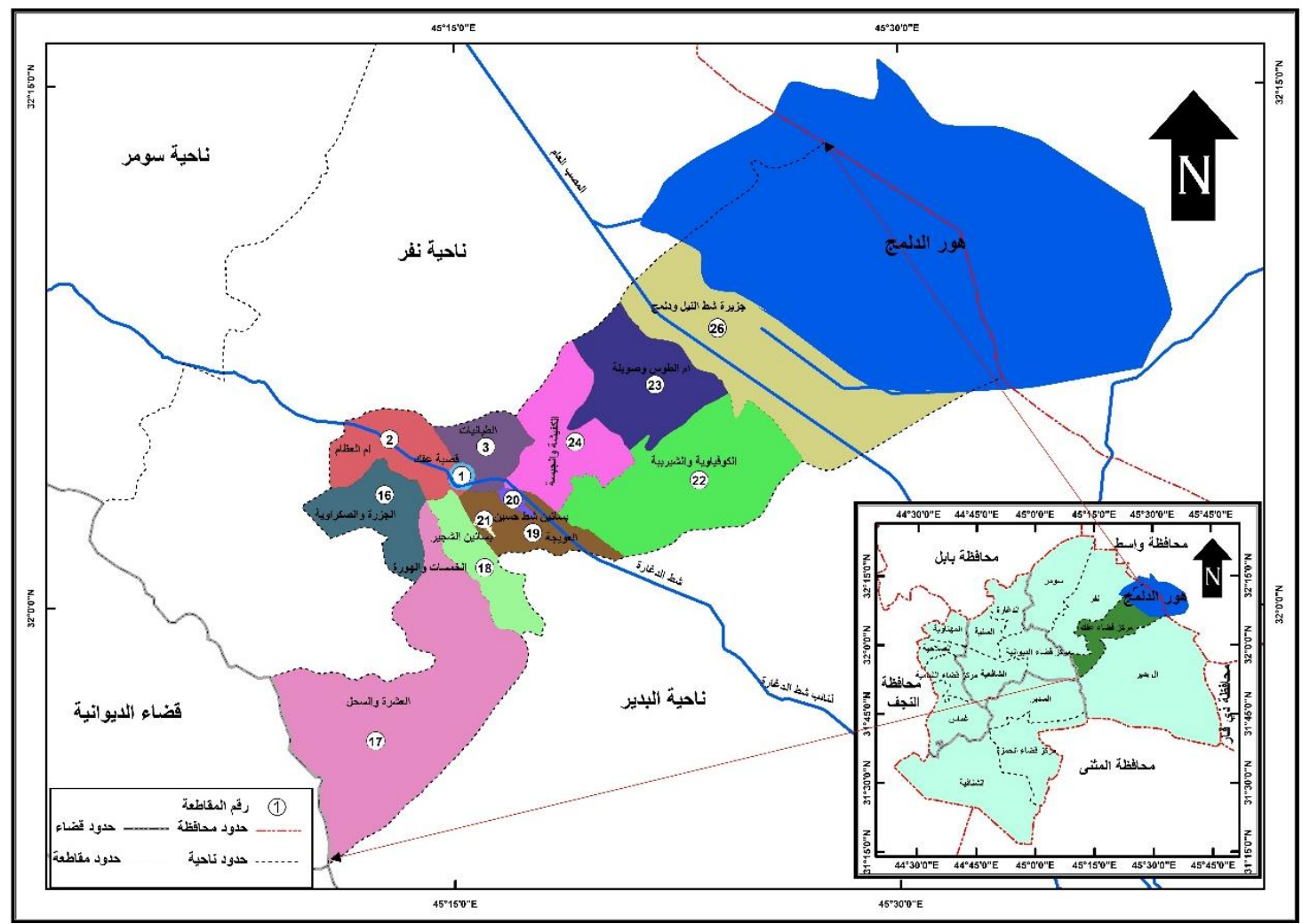

المصدر: اعتماداً على: 1. وزارة الموارد المائية، المديرية العامة للمساحة، قسم انتاج الخرائط الرقمية

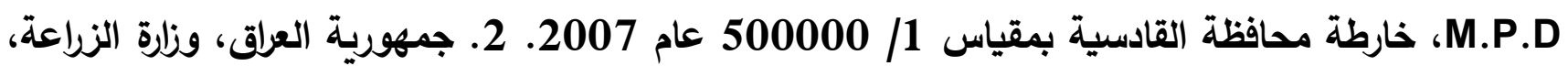
مديرية زراعة محافظة القادسية، خارطة مقاطعات محافظة القادسية بمقياس 1/ 1 1 500000 عام 2012. 
مجلة أبحاث ميسان ، المجلد السادس عشر، العدد الثاني والثلاثون ، كانون الأول، السنة

جدول (1) أرقام وأسماء المقاطعات الزراعية في منطقة الدراسة

\begin{tabular}{|c|c|c|c|c|c|}
\hline أسم المقاطعة & رقاطعة & أسم المقاطعة & رقما & أسم المقاطعة & رقما \\
\hline أم الطوس وصويلة & 23 & الخمسات & 18 & قصبة عفك & 1 \\
\hline الكفيشة والجبسة & 24 & العويجة & 19 & أم العظام & 2 \\
\hline \multirow{3}{*}{ جزيرة شط النيل } & \multirow{3}{*}{26} & بساتين شط & 20 & الطيانيات & 3 \\
\hline & & الثباتين & 21 & والصكراوية & 16 \\
\hline & & والكوفياية & 22 & والعشرة & 17 \\
\hline
\end{tabular}

المصدر: اعتماداً على خريطة (1).

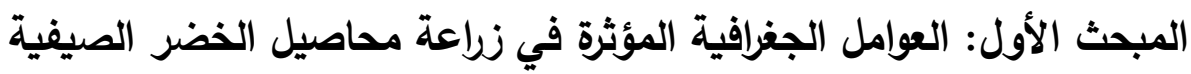

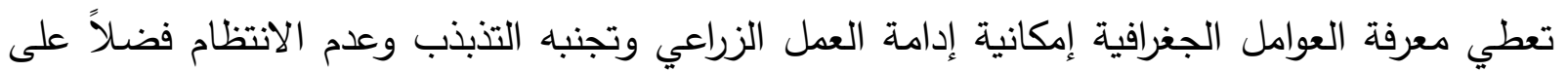

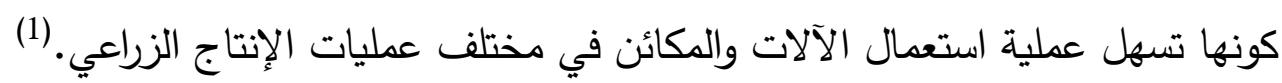
أولاً: العوامل الطبيعية:

1. التركيب الجيولوجي: يكثف العامل الجيولوجي عن نوعية وطبيعة وتركيب الصخور التي تحددها العصور

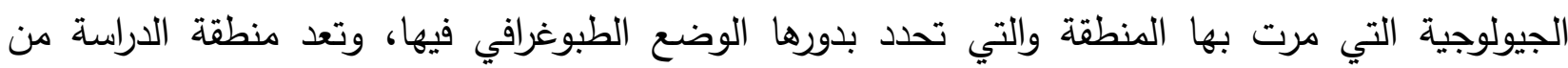
التكوينات الحديثة ضمن سهل العراق الفيضي وساعد هذا التكوين على أن تتميز بخصوبة التربة وسهولة أداء العمليات الزراعية من حراثة وشق قنوات المياه مما كان له دور في إضفاء الصفة الزراعية على منطقة الدراسة، كما توجد فيها بعض تكوينات ترسبات المستنقعات في الجزء الأوسط منها وترسبات المنخفضات ونسات المطمورة في الجهات الجنوبية الغربية، وبعض الترسبات الريحية والكثبان الرملية في جزئها الثرقي. (2) خريطة 
مجلة أبحاث ميسان ، المجلد السادس عشر، العدد الثاني والثلاثون ، كانون الأول، السنة

خريطة (2) التركيب الجيولوجي في منطقة الدراسة

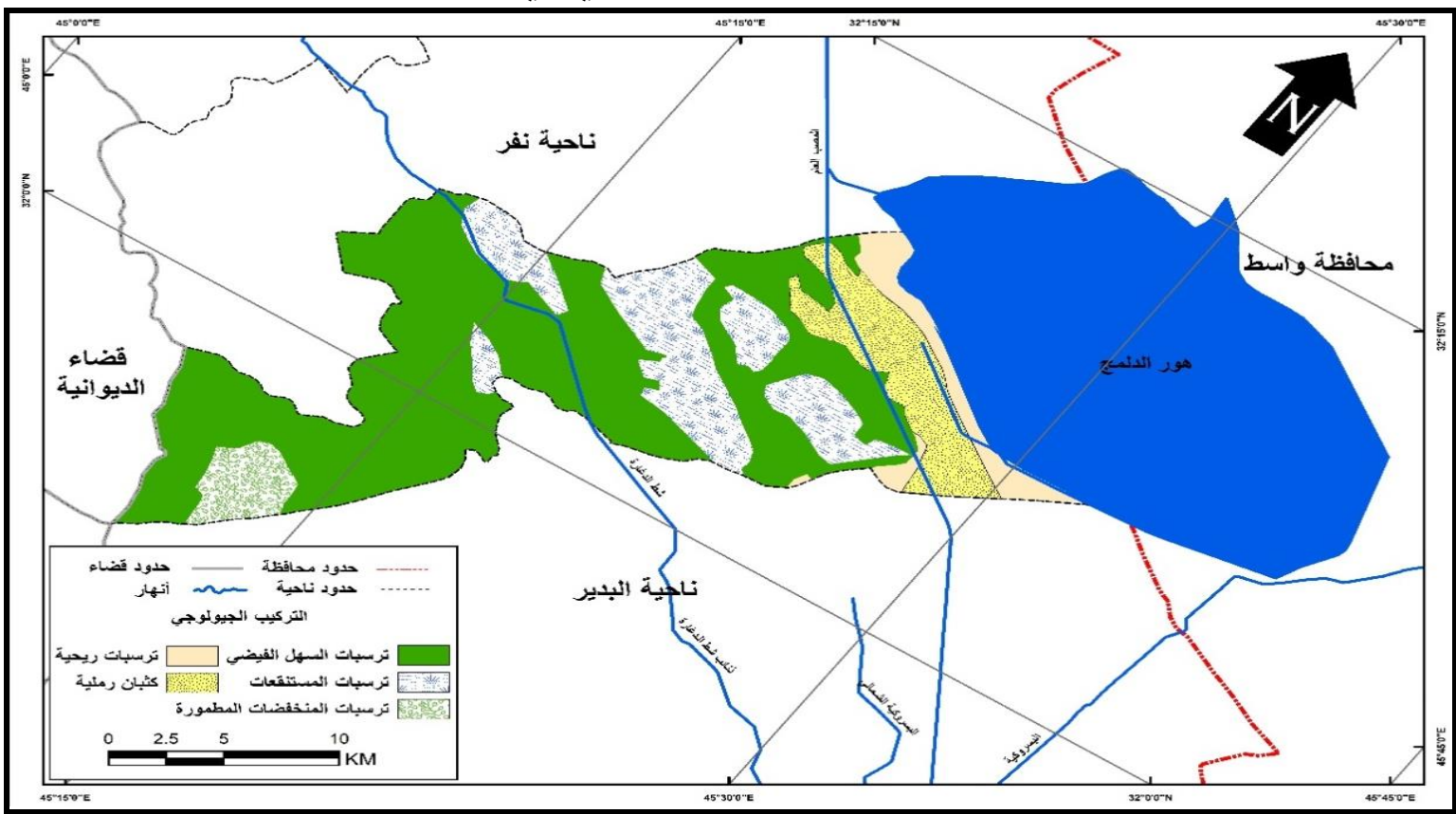

المصدر: اعتماداً على جمهورية العراق، وزارة البلديات والأثغال العامة، المديرية العامة للتخطيط العمراني، مديرية التخطيط العمراني في محافظة القادية، الخطة الهيكلية لمحافظة القادسية، الخارطة الجيولوجية بمقياس 1 / مديره التطبط

2. السطح : يعد السطح من العوامل المؤثرة في الإنتاج الزراعي، إذ يتحدد تأثيره بارتفاعه وانخفاضه عن الإنا

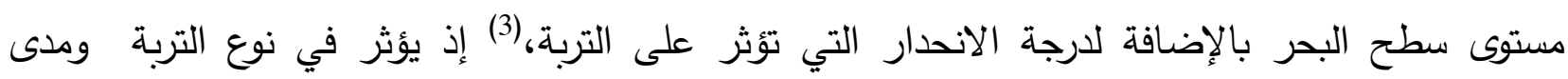

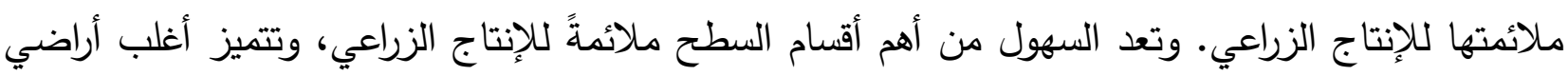

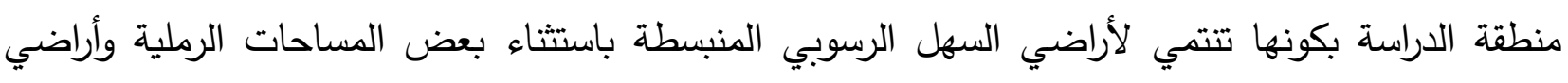

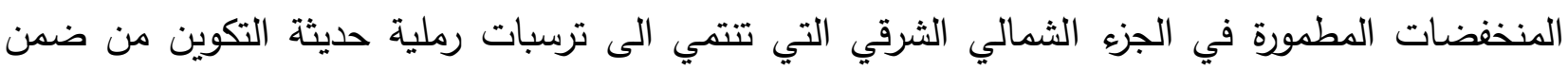

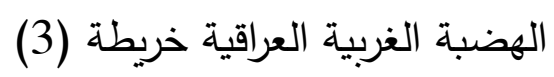


خريطة (3) أقسام مظاهر السطح في منطقة الدراسة

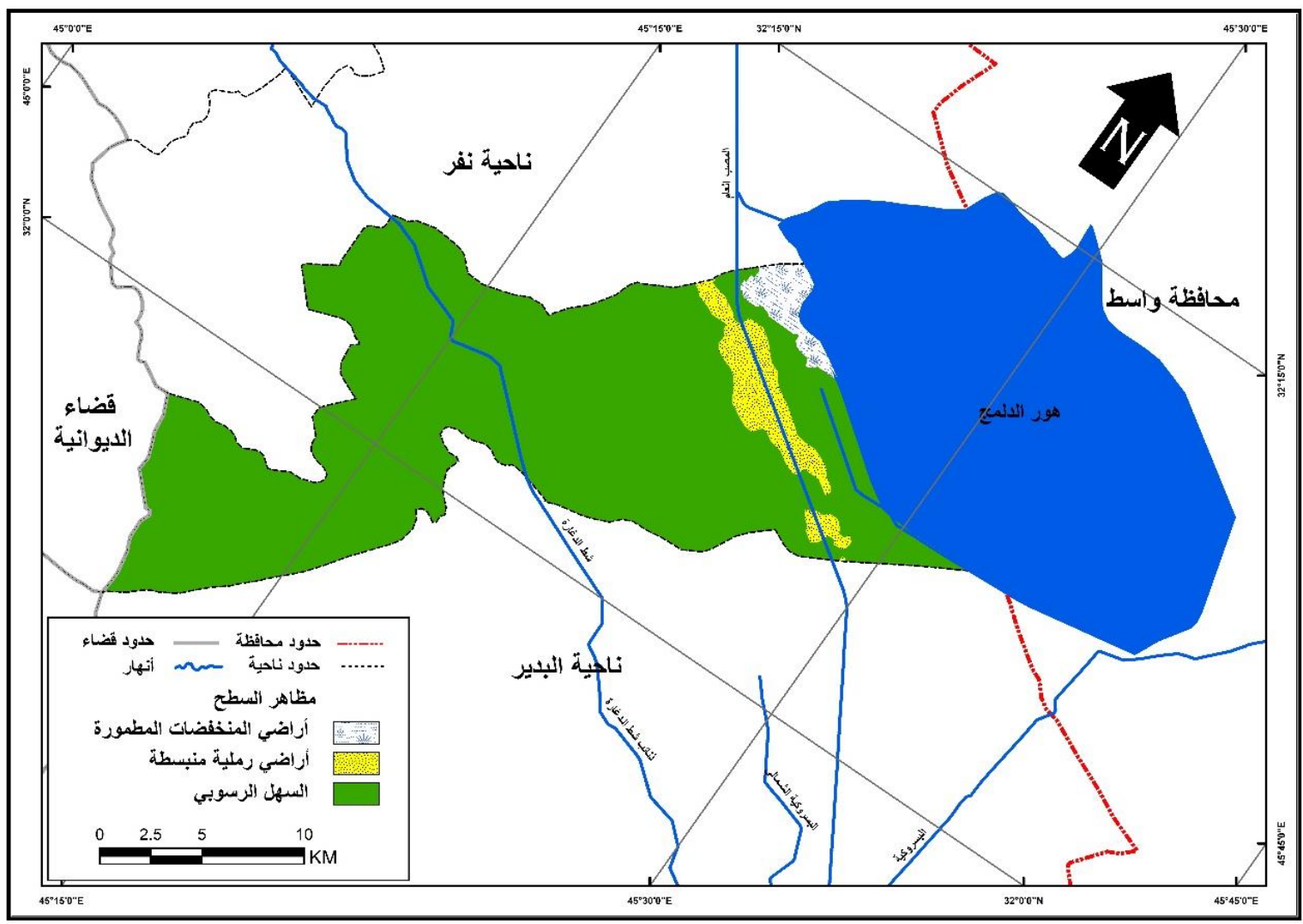

المصدر: اعتماداً على جمهورية العرق، وزارة البلديات والأثشال العامة، المديرية العامة للتخطيط العمراني،

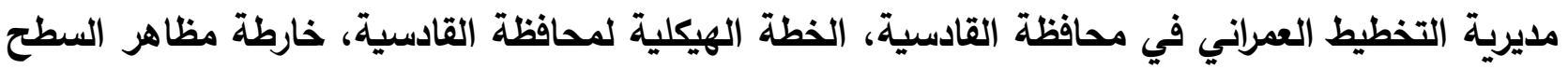

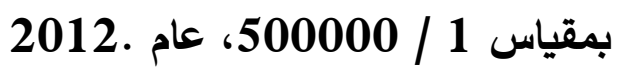
2. المناخ : يؤدي المناخ بعناصره الدختلفة دوراً رئيسياً مهماً في تحديد أنماط ومناطق الإنتاج الزراعي، إذ إن

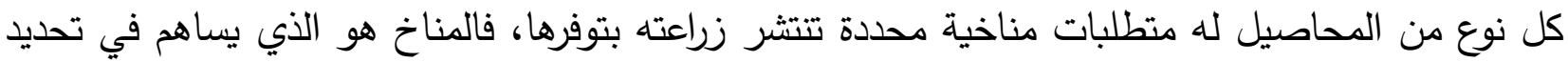

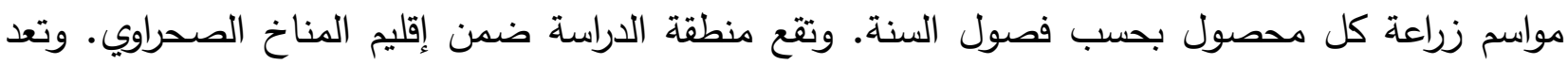
الحرارة من أهم عناصر المناخ المؤثرة في جميع العمليات الفسيولوجية والحيوية للنبات، ويكون تأثيرها بصورة

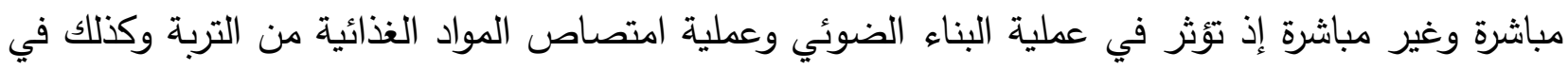

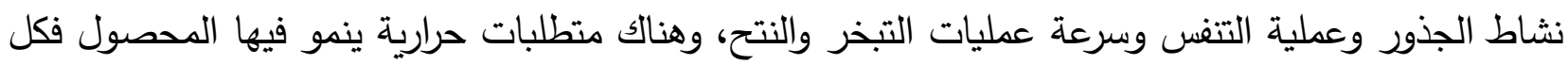

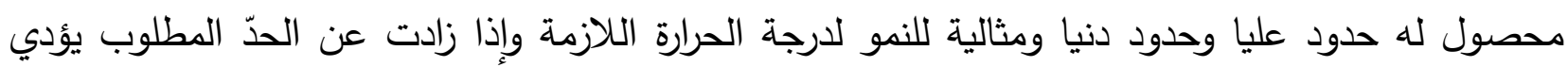
ذلك إلى تغير في النبات يبدأ من المظهر الخارجي، (4) وبيين جدول (2) إن أدنى درجة حرارة لنمو محاصيل لإنيل

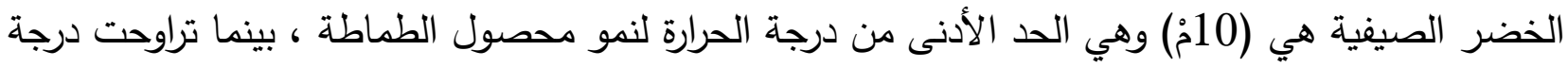

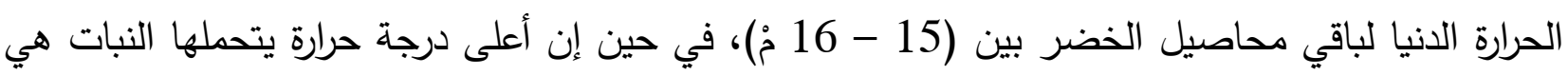




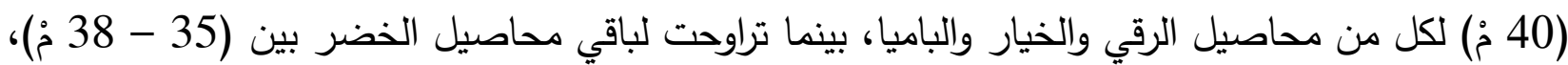

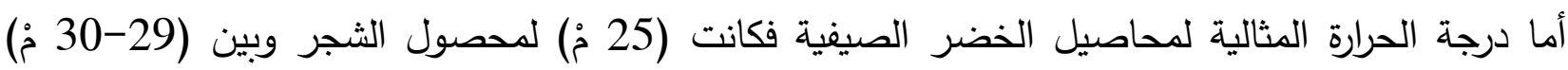
لمحاصيل البطيخ والفلفل والباذنجان والطماطة في حين بلغت (35 مج) لكل من الرقي والخيار . جدول (2) المتطلبات الحرارية لدحاصيل الخضر الصيفية

\begin{tabular}{|c|c|c|c|c|c|c|c|c|}
\hline ميا & | الشر & |الطما & الخيار & الباذنجا & الفلفل & البطيخ & الرقي & المحصول \\
\hline 15 & 16 & 10 & $\begin{array}{c}-15 \\
16\end{array}$ & $16-15$ & $\begin{array}{c}-15 \\
16\end{array}$ & $\begin{array}{c}-15 \\
16\end{array}$ & $\begin{array}{c}-15 \\
16\end{array}$ & دالدة الحرارة \\
\hline 40 & 38 & \begin{tabular}{c||}
-35 \\
38
\end{tabular} & 40 & $38-35$ & $\begin{array}{c}-35 \\
38\end{array}$ & 38 & 40 & درجة الحرارة \\
\hline 35 & 25 & 29,5 & 35 & 29,5 & 29.5 & 30 & 35 & دالمثالية (مْ) \\
\hline \begin{tabular}{l||}
11 \\
20
\end{tabular} & $\begin{array}{l}10 \\
50\end{array}$ & $\begin{array}{c}160 \\
0\end{array}$ & $\begin{array}{c}111 \\
5\end{array}$ & $\begin{array}{c}1978 \\
5\end{array}$ & 1050 & $\begin{array}{c}112 \\
5\end{array}$ & $\begin{array}{c}110 \\
0\end{array}$ & 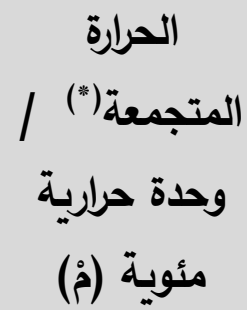 \\
\hline
\end{tabular}

(الحرار المتجمعة : ويقصد بها مجموع الوحدات او درجات الحرارة اللازمة للوصول بالمحصول الى مرحلة

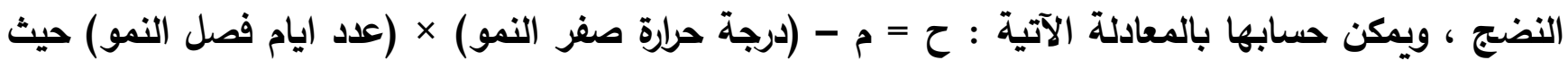

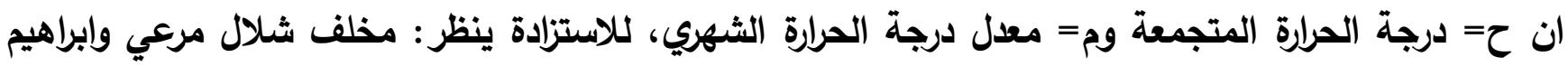
محمد حسون القصاب ، جغرافية الزراعة ، دار الكتب للطباعة وإلنشر ،الموصل ، 1996، ص22

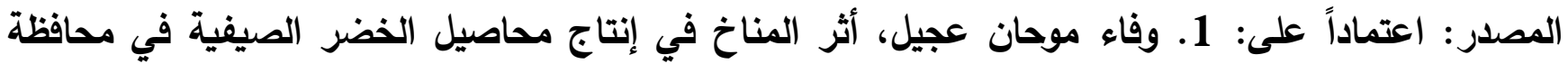

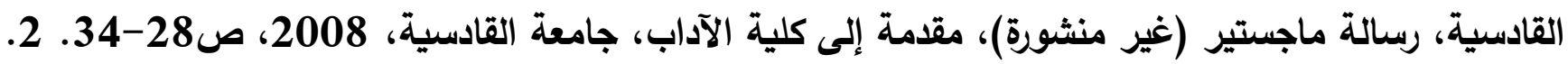

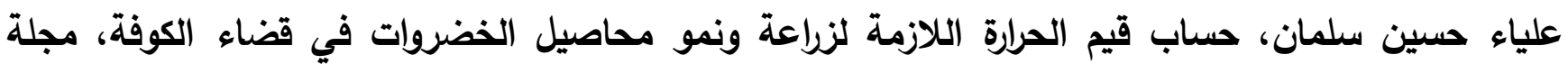
معين، جامعة الكفيل، العدد 4، 2015، صنان، 211.

3. التربة: تعد التربة عبارة عن مركب أو خليط مفتت من مواد عضوية وصخرية وماء وهواء تتمو فيها

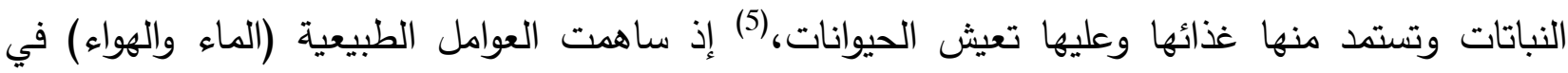
تفتيت الصخور وحولتها لطبقة هشة يختلف سمكها من منطقة إلى أخرى ويتراوح هذا السمك بين بضع من 
السنتيمترات إلى عدة أمتار،(6) وتعد التربة المزيجية الغرينية الخصبة الجيدة الصرف أفضل أنواع الترب لزراعة الخضر،(7) وتغطي معظم مساحات منطقة الدراسة تربة أحواض الأنهار، كما تغطي تربة أكتاف الأنهار

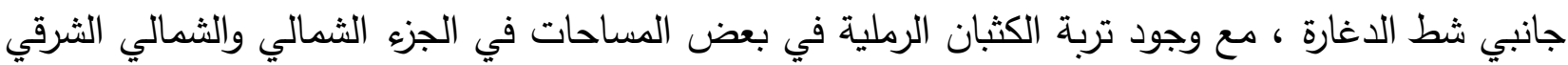

خريطة (4).

4. الموارد المائية: لا يمكن تصور قيام أي نثاط زراعي بدون الموارد المائية التي تثمل مياه الأمطار

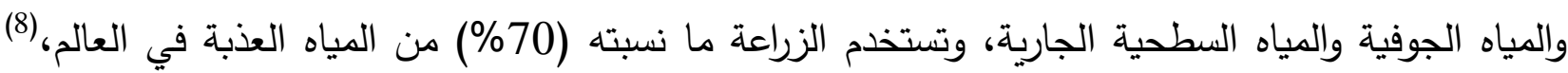

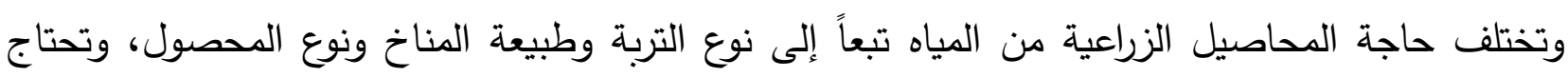
محاصيل الخضر الصيفية إلى كميات كبيرة من المياه تقدر بنحو (5819 م²/دونم). (9) وتتميز منطقة الدراسة

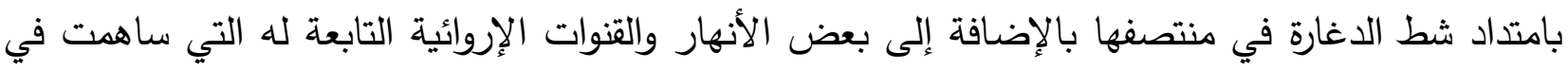
زراعة المحاصيل الزراعية في منطقة الدراسة وبضمنها محاصيل الخضر الصيفية التي تركزت أغلب

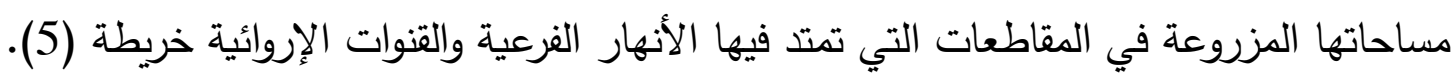

خريطة (4) أصناف الترب في منطقة الدراسة

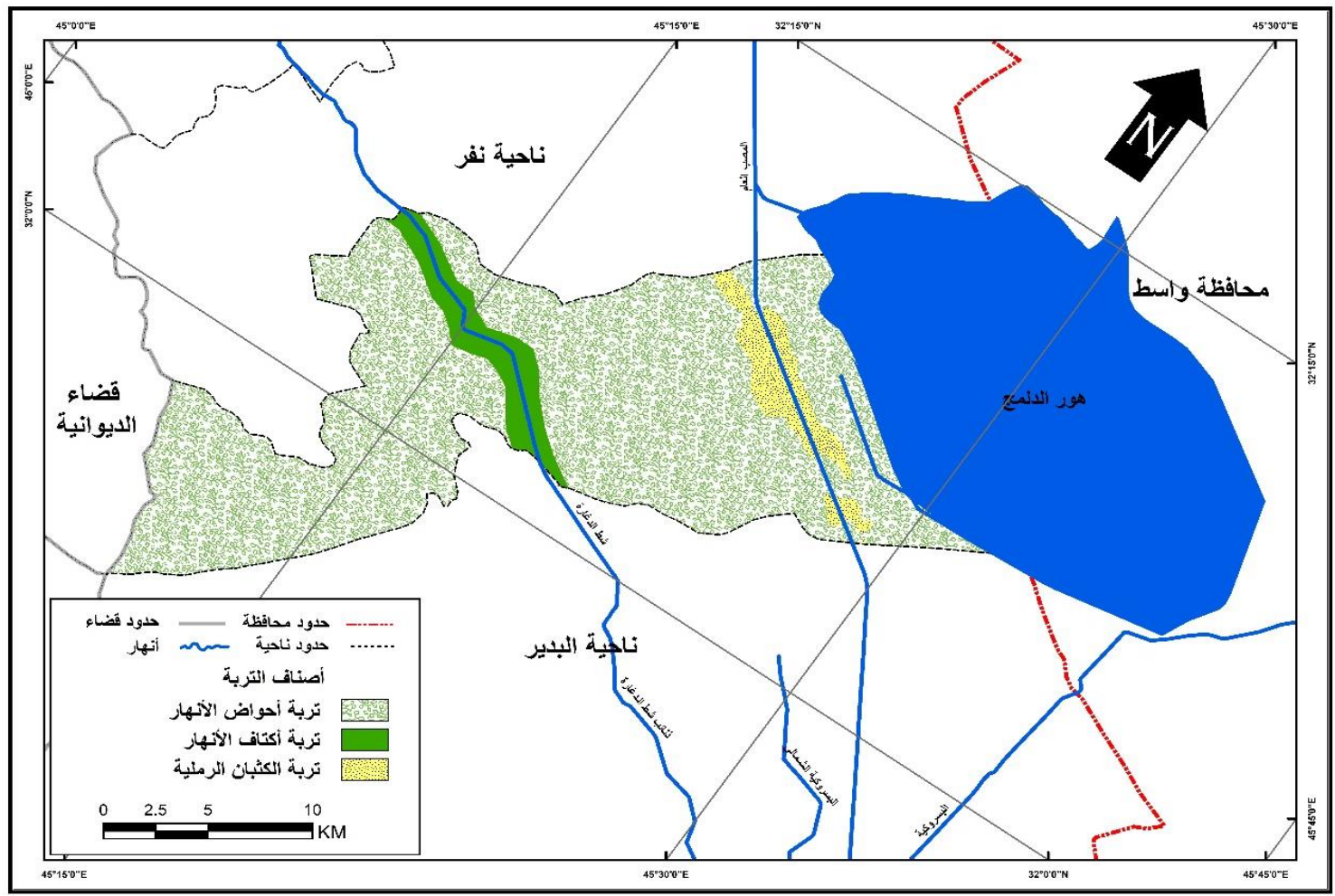

المصدر: اعتماداً على: جمهورية العراق، وزارة البلايات والأثغال العامة، المديرية العامة للتخطيط العمراني، مديرية التخطيط العمراني في محافظة القادسية، الخطة الهيكلية لمحافظة القادسية، خارطة التربة التبادية بمقياس 1/ 5لميه 
مجلة أبحاث ميسان ، المجلد السادس عشر، العدد الثاني والثلاثون ، كانون الأول، السنة 2020

خريطة (5) الموارد المائية السطحية في منطقة الدراسة

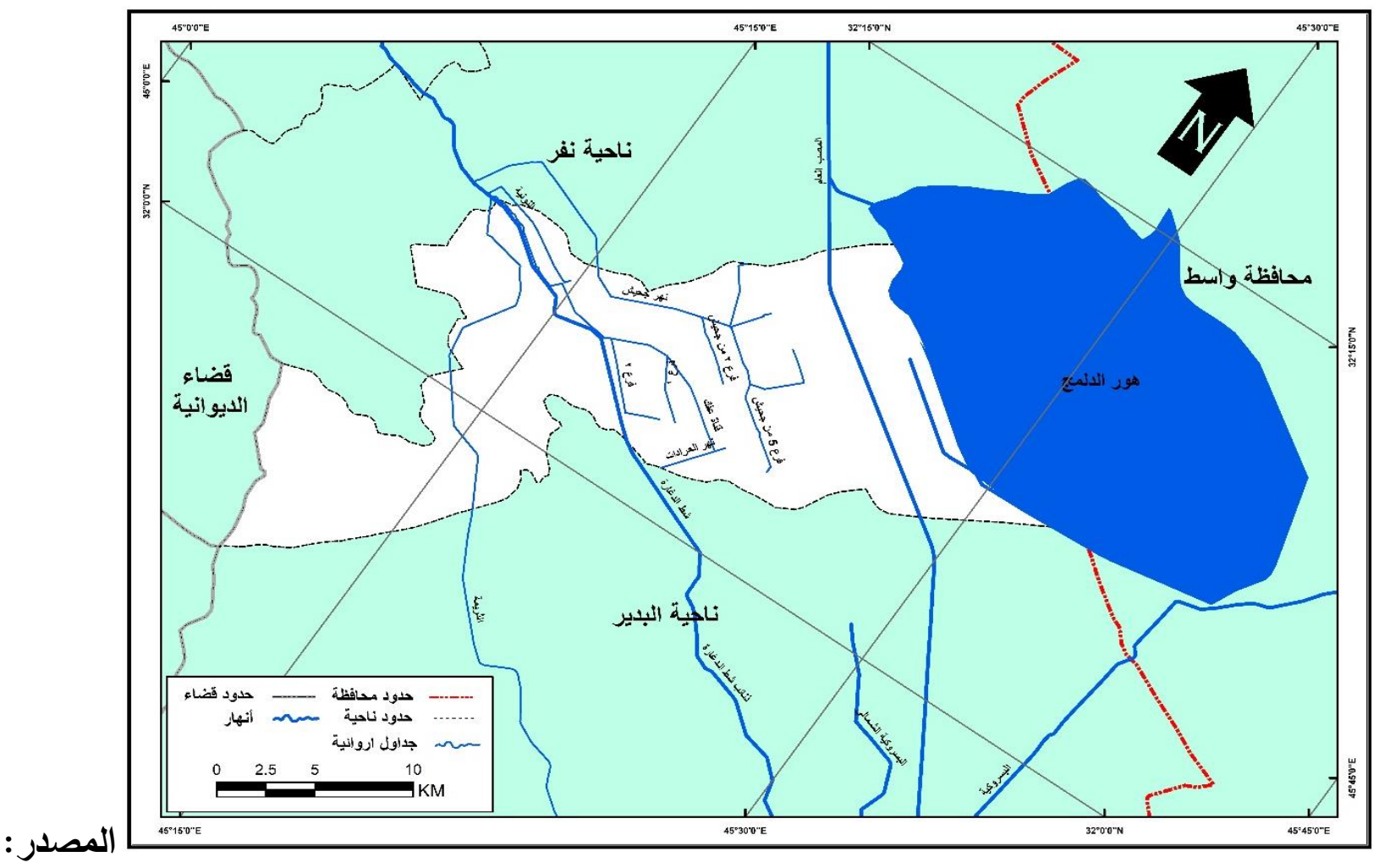

اعتماداً على وزارة الري، مديرية الموارد المائية في محافظة القادية، شعبة ري عفك، خريطة الارواء في قضاء عفك عام 2018.

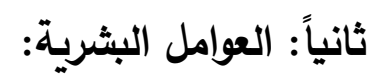
1. اليد العاملة: يعد السكان من أهم مقومات الإنتاج فهو العامل الرئيسي الذي يشكل جئي جميع الموارد فهو

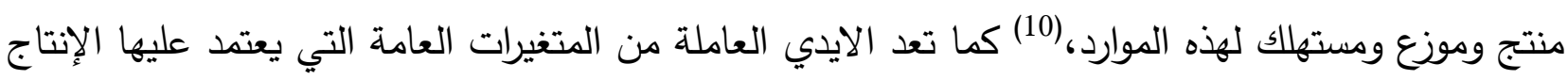

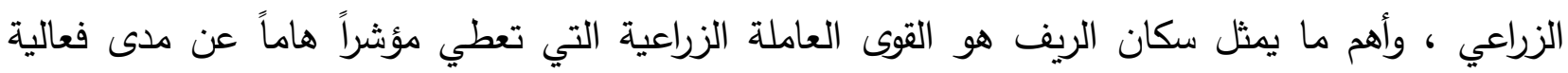

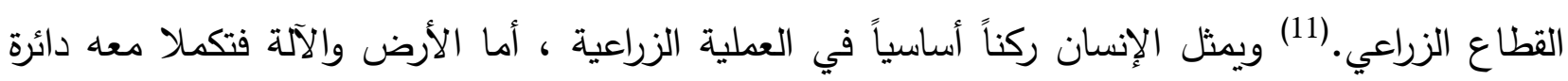

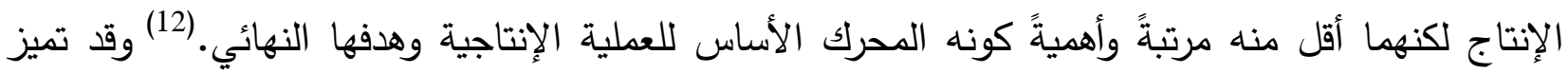

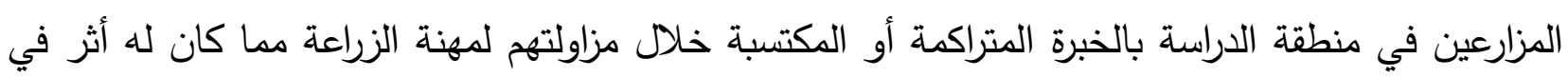

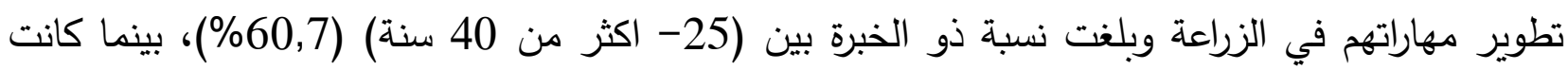

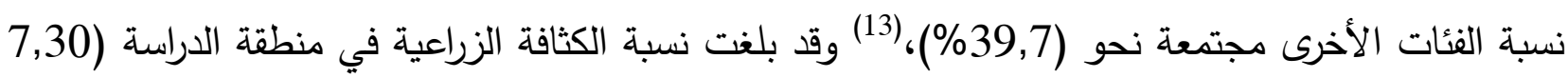

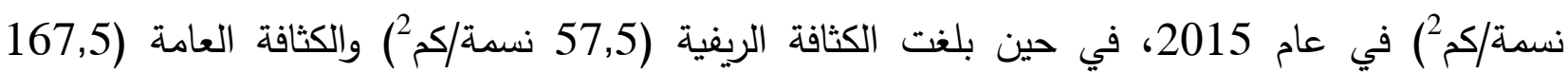

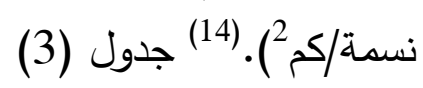


مجلة أبحاث ميسان ، المجلد السادس عشر، العدد الثاني والثلاثون ، كانون الأول، السنة

جدول (3) تصنيف الكثافات الزراعية بحسب الدرجة المعيارية على مستوى المقاطعات الزراعية في منطقة الدراسة لعام 2015

\begin{tabular}{|c|c|c|c|c|}
\hline أقل من 50 - - 0 & $\begin{array}{c}-0,49 \\
-0,01\end{array}$ & $0,01-0,49$ & \multicolumn{2}{|c|}{ أكثر من + 0.50} \\
\hline جزيرة شط النيل & - & الكفيشة والجبسة & \multicolumn{2}{|c|}{ الجزراوية } \\
\hline أم الطوس وصويلة & - & الكفياية والثربيية & \multicolumn{2}{|c|}{ الطيانيات } \\
\hline- & - & العشرة والسحل & \multicolumn{2}{|c|}{ بساتين شط حسين } \\
\hline- & - & - & \multicolumn{2}{|c|}{ بساتين الثجير } \\
\hline- & - & - & \multicolumn{2}{|c|}{ الخمسات واللهورة } \\
\hline- & - & - & \multicolumn{2}{|c|}{ أم العظام } \\
\hline- & - & - & \multicolumn{2}{|c|}{ العويجة } \\
\hline 2 & $\mathbf{0}$ & 3 & 7 & المجموع \\
\hline 16,67 & $\mathbf{0}$ & 25 & 58,33 & $\begin{array}{c}\text { النسبة } \\
\text { \% }\end{array}$ \\
\hline
\end{tabular}

المصدر: عباس حمزة علي الثمري، التخطيط الاستراتيجي للتنمية الريفية في قضاء عفك، أطروحة

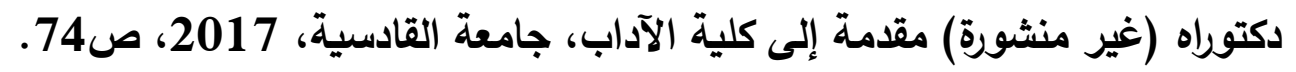

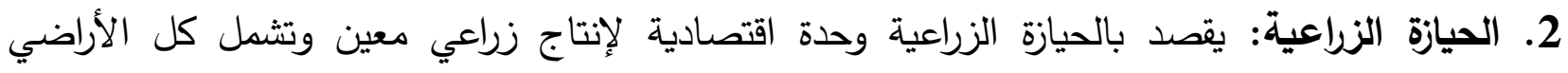

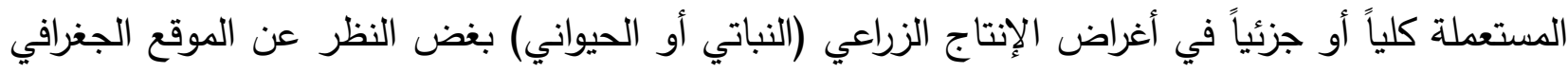

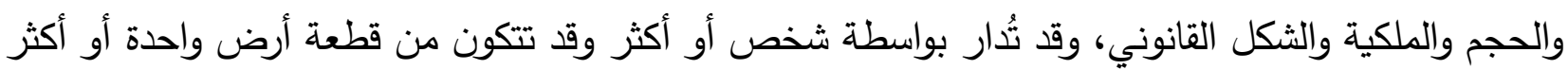

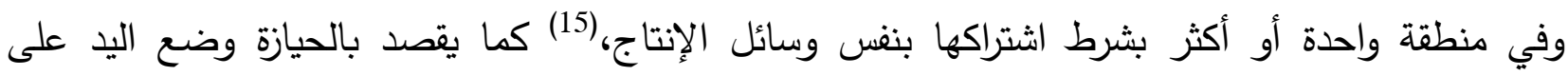

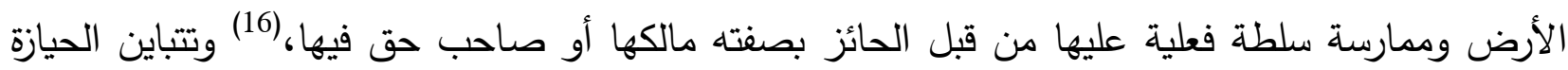

الزراعية في منطقة الدراسة كما مبين في الجدول (4). جدول (4) حجم الحيازة الزراعية في منطقة الدراسة (دونم)

\begin{tabular}{|c|c|c|c|c|c|c|c|}
\hline$\%$ & $\begin{array}{r}90 \\
\text { فاكثر }\end{array}$ & $\%$ & $\begin{array}{c}-31 \\
60\end{array}$ & $\%$ & $\begin{array}{c}-16 \\
30\end{array}$ & $\%$ & اقل من 15 \\
\hline
\end{tabular}


مجلة أبحاث ميسان ، المجلد السادس عشر، العدد الثاني والثلاثون ، كانون الأول، السنة

\begin{tabular}{||l|l|l|l|l|l|l|l||}
\hline \hline 24,7 & 15 & 4,5 & 2 & 27,3 & 12 & 34 & 15 \\
\hline
\end{tabular}

المصدر: حسين ذياب محمد وعباس حمزة علي، تقييم التنمية الزراعية في ريف مركز قضاء عفك في

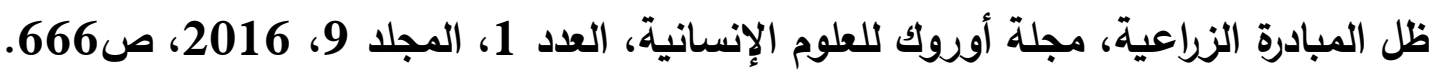

3. المكنتة الزراعية: تسهم في اختزال كلفة ومشاق العمل اليدوي، كما يترتب على استعمالها رفع إنتاجية وكفاءة العمل إذ تساعد على انخفاض كلفة العمل وتزيد من الإنتاج وتحسن نوعيته كما يمكنها المساهمة في زيادة المساحات الزراعية التي تستعمل العمل اليدوي فيها، ويقتصر دورها في منطقة الدراسة على الإسى حراثة

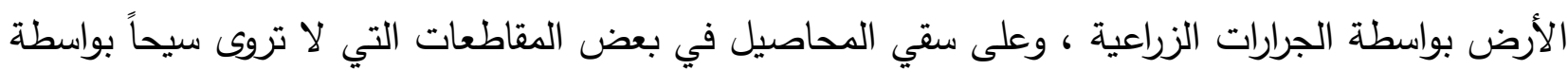
مضخات المياه ، اما باقي المتطلبات الزراعية فهي تعتمد على الايدي العاملة فقط.

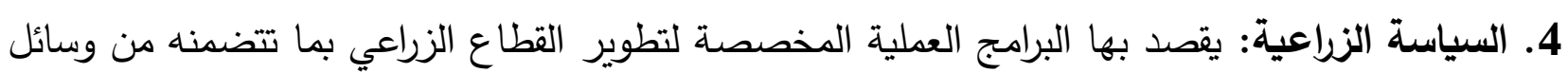
وخطط زراعية مناسبة لتحقيق أكبر قدر من الرفاهية المادية والمعنوية للسكان بوجه عام للعاملين بالزراعة

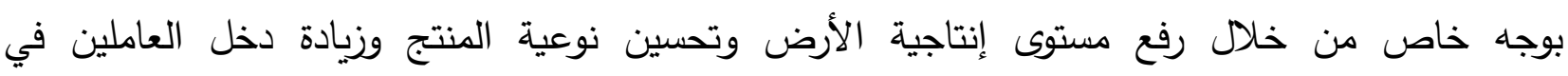
الزراعة، (17) يتمثل دور المؤسسات الحكومية ذات العلاقة بتوزيع البذور والارشاد الزراعي والتسليف الزراعي ولكن في السنوات الاخيرة لم يكن دورها كبيراً في التشجيع على زراعة محاصيل الخضر الصيفية في منطقة لته الاراسة لذا تعاني من قلة الاهتمام والدعم الحكومي في الوقت الحاضر . 5. طرق النقل: تعد طرق النقل من العوامل المهمة في الإنتاج الزراعي إذ تعد متممة للإنتاج حيث تحدد

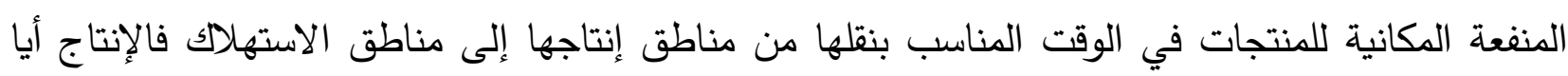

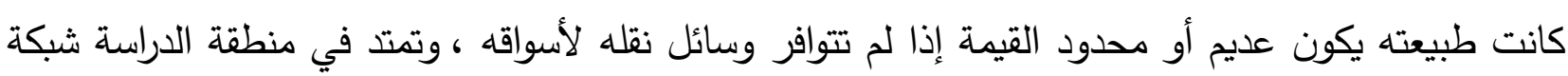
من الطرق البرية المعبدة والترابية، تتمثل بالطريق الرئيس الذي يربطها بقضاء الديوانية وناحية البدير،

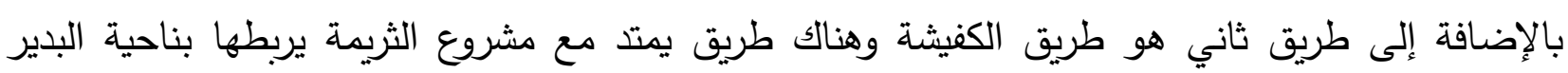
والثاني طريق الثريمة رقم واحد ويربطها بناحية البدير ايضاً بالإضافة إلى بعض الطرق الريفية غير المعبدة خريطة (6).

المبحث الثاني : التوزيع الجغرافي لزراعة الخضر في قضاء عفك تثمل محاصيل الخضر مجموعة كبيرة من النباتات ذات القيمة التجارية والغذائية. وتحتوي محاصيل الخضر على الفيتامينات والمعادن الضرورية لجسم الإنسان ، فضلاً عن احتوائها على الكربوهيدرات والدهنيات والبروتينات ولذلك تأتي بالمرتبة الثانية بعد الحبوب من حيث أهيتها الغذائية. 
خريطة (6) شبكة طرق النقل في منطقة الدراسة

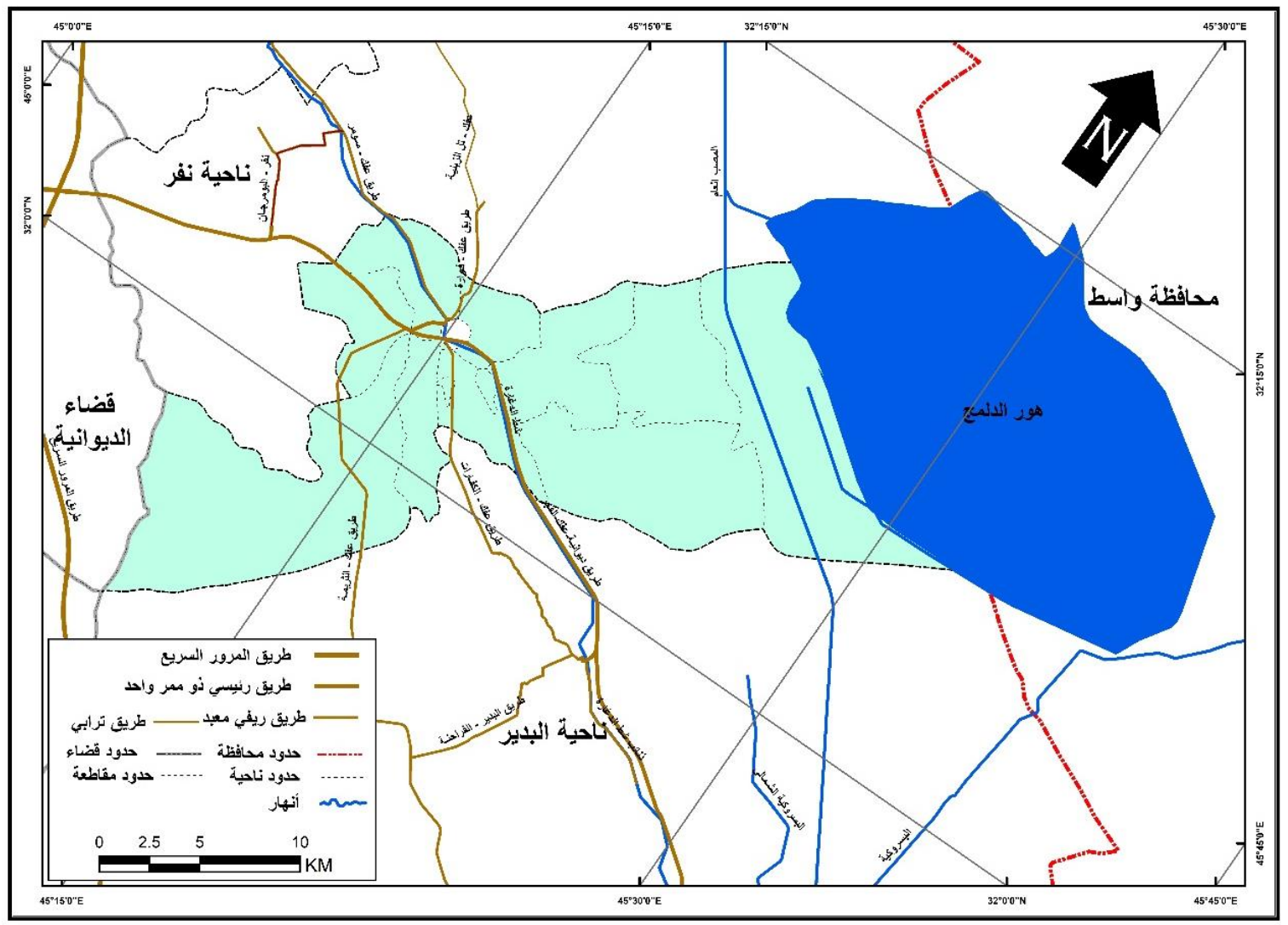

المصدر: اعتماداً على مرئية القمر الاصطناعي لمنطقة الدراسة باستخدام برنامج Arc GIS10.4 وبرنامج sasplanet بدقة 60 سم لعام 2018.

أولاً: المساحات المزروعة بمحاصيل الخضر : 1. التوزيع النسبي لمجموع المساحات المزروعة بمحاصيل الخضر الصيفية: بلغ مجموع المساحات

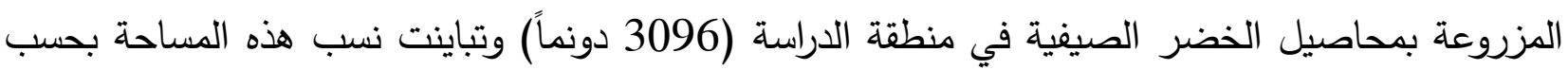

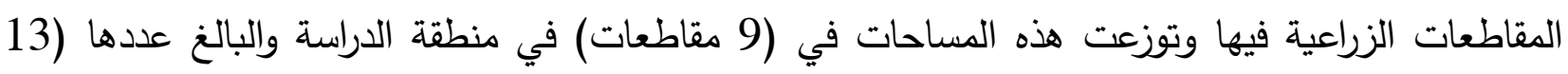

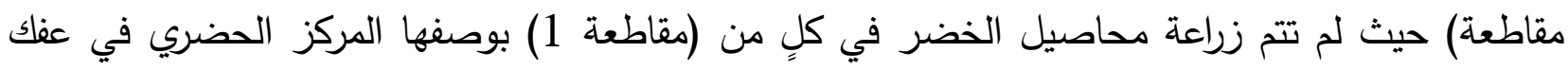
وكذلك لم تزرع هذه المحاصيل في مقاطعتي (26 و 21) بسبب شحة المياه فيها. أما من حيث نسب المساحات المزروعة بمحاصيل الخضر فقد تبوأت (مقاطعة 17) المرتبة الأولى بمساحة

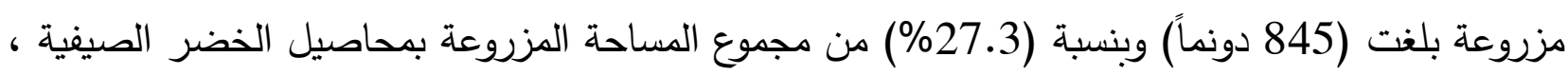
تلتها (مقاطعة 18) بمساحة مزروعة بلغت (555 دونماً) وبنسبة (17,9\%) من من مجموع المساحة المزروعة (لماتة 
بمحاصيل الخضر الصيفية ، ثم (مقاطعة 16) التي بلغت المساحة المزروعة فيها (467 دونماً) وبنسبة (15,1\%) من المساحة المزروعة بمحاصيل الخضر الصيفية ، إذ يعزى سبب تصدر هذه المقاطعات

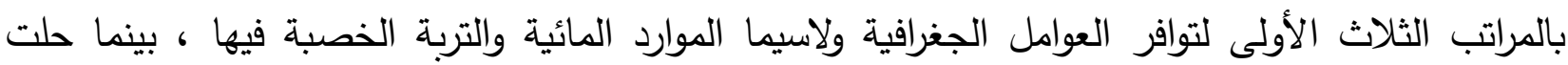

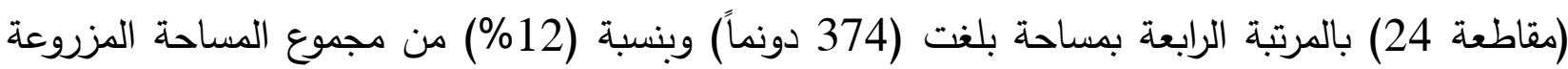
بمحاصيل الخضر الصيفية ، في ما كانت أقل مساحة مزروعة في منطقة الدراسة في (مقاطعة 23) بمساحة بلغت (108 دونماً) وبنسبة (3,5\%) من المساحة المزروعة بمحاصيل الخضر الصيفية ، وحلت (مقاطعة 19) بالمرتبة قبل الأخيرة من حيث المساحة المزروعة بمحاصيل الخضر الصيفية بمساحة بلغت (166)

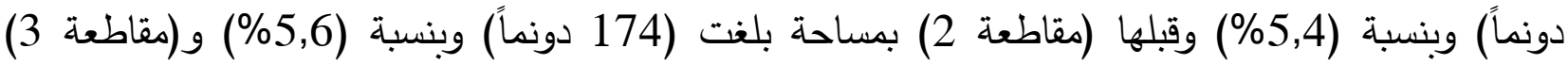

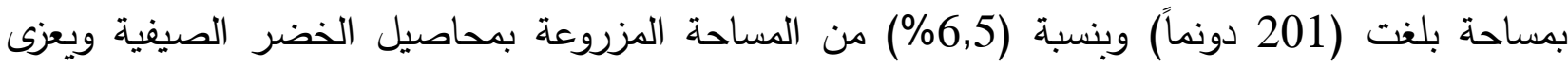

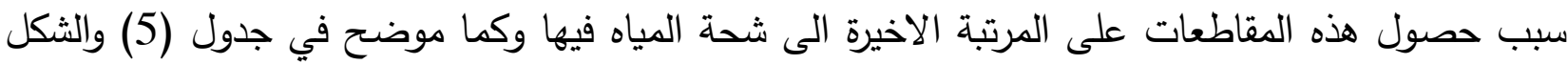

جدول (5) مجموع المساحات المزروعة بمحاصيل الخضر الصيفية حسب المقاطعات الزراعية ونسبتها المئوية في منطقة الدراسة عام 2019

\begin{tabular}{|c|c|c|c|c|c|}
\hline$\%$ & المزروعة بمحاصيل المساحة & المقاطعة رقم & $\%$ & المزروعة بمحاصيل المساحة & المقاطعة \\
\hline 5,4 & 166 & 19 & 5,6 & 174 & 2 \\
\hline 6,6 & 206 & 22 & 6,5 & 201 & 3 \\
\hline 3,5 & 108 & 23 & 15,1 & 467 & 16 \\
\hline 12,1 & 374 & 24 & 27,3 & 845 & 17 \\
\hline 100 & 3096 & المجموع & 17,9 & 555 & 18 \\
\hline
\end{tabular}

المصدر: اعتماداً على مديرية زراعة القادسية، شعبة زراعة عفك، قسم الإنتاج النباتي، 2019، بيانات غير منشورة.

شكل (1) التوزيع النسبي لمجموع المساحات المزروعة بمحاصيل الخضر الصيفية على مستوى المقاطعات عام 2019 
مجلة أبحاث ميسان ، المجلد السادس عشر، العدد الثاني والثلاثون ، كانون الأول، السنة 2020

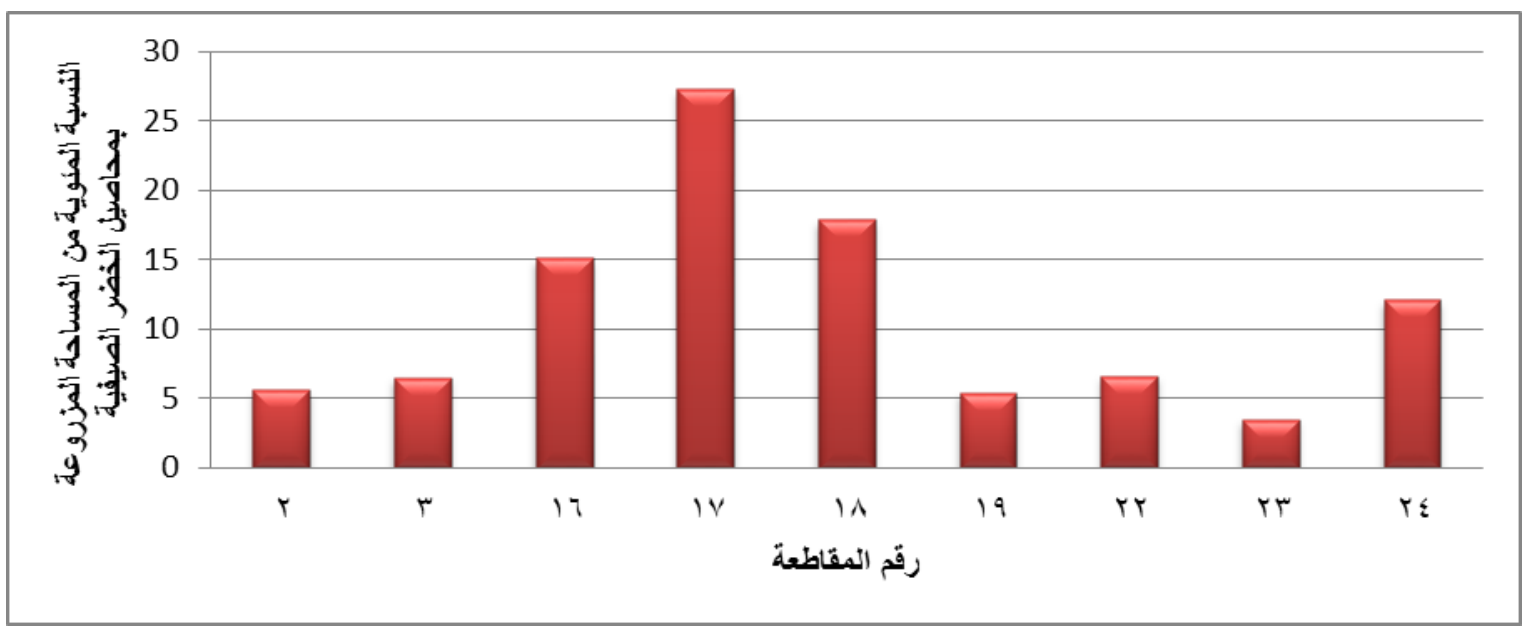

المصدر: اعتماداً على بيانات جدول (5).

2. التوزيع النسبي لمجموع المساحات المزروعة بكل محصول: يتبين من الجدول (6) والثكل (2) إن أكبر مساحة مزروعة بمحاصيل الخضر الصيفية في منطقة الدراسة شغلها محصول الرقي بمساحة بلغت (1500 دونماً) من مجموع المساحة المزروعة بمداصئ بداصيل

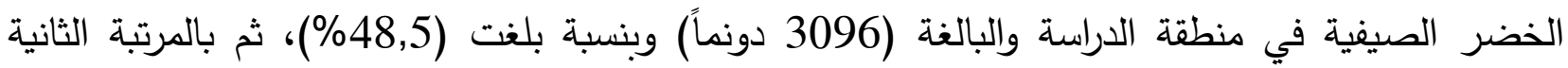
المساحة المزروعة بمحصول البطيخ بمساحة بلغت (1000 دونماً) وبنسبة (32,3\%) من مجموعة المبنة المساحة

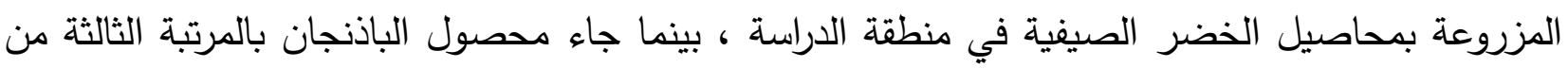
حيث المساحة المزروعة بمساحة بلغت (250 دونماً) وبنسبة (8,1\%) من مجموع المساحة المزروعة فيناء

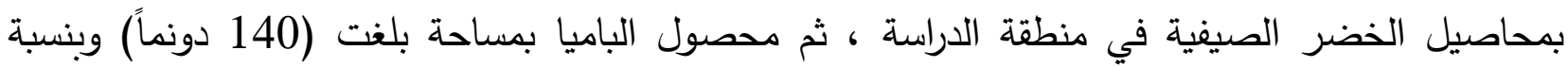
(4,5\%) ثم محصول الخيار بمساحة بلغت (86 دونماً) وبنسبة (2,8\%) من مجموع المساحة المزروعة

بمحاصيل الخضر الصيفية. جدول (6) التوزيع النسبي للمساحات المزروعة بمحاصيل الخضر الصيفية بـ (الدونم) ونسبها المئوية حسب المحصول في منطقة الدراسة عام 2019

\begin{tabular}{|c|c|c|c|c|c|}
\hline$\%$ & المساحة & المحصول & $\%$ & المساحة & المحصول \\
\hline 1,6 & 50 & لوبياء & 48,5 & 1500 & رقي \\
\hline 0,6 & 20 & طماطة & 32,3 & 1000 & بطيخ \\
\hline 0,3 & 10 & فلفل & 4,5 & 140 & باميا \\
\hline 0,3 & 10 & شجر & 2,8 & 86 & خيار \\
\hline
\end{tabular}


مجلة أبحاث ميسان ، المجلد السادس عشر، العدد الثاني والثلاثون ، كانون الأول، السنة 2020

\begin{tabular}{|c|c|c|c|c|c|}
\hline 1 & 30 & خضر ورقية & 8,1 & 250 & باذنجان \\
\hline 100 & 3096 & \multicolumn{4}{|c|}{ المجموع } \\
\hline
\end{tabular}

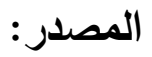
اعتماداً على مديرية زراعة القادسية، شعبة زراعة عفك، قسم الإنتاج النباتي، 2019، بيانات غير منشورة. شكل (2) التوزيع النسبي للمساحات المزروعة بمحاصيل الخضر بحسب المحصول في منطقة الدراسة عام 2019

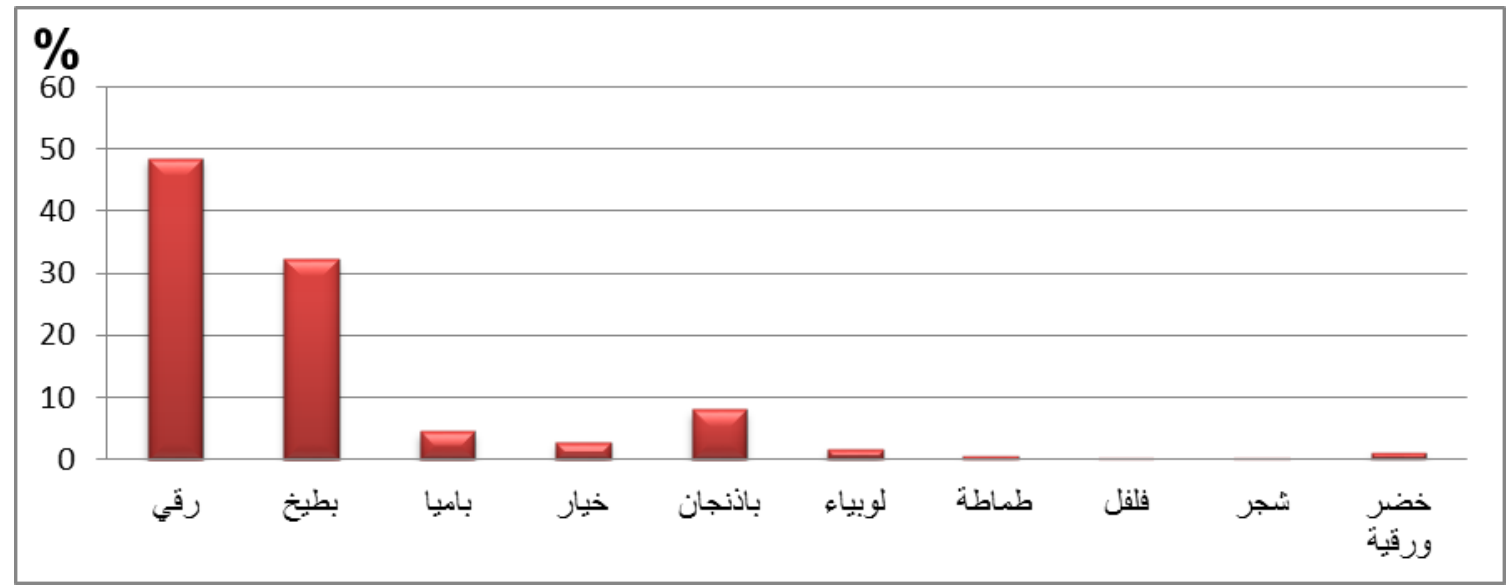

المصدر: اعتماداً على بيانات جدول (6)

أما أقل المساحات المزروعة بمحاصيل الخضر الصيفية فقد شغلها محصولي الفلفل والخضر الورقية وبمساحة (10 دونماً) لكلٍ منها وبنسبة (0,3\%) من المساحة المزروعة بمحاصيل الخضر الصيفية، وبالمرتبة قبل الأخيرة حل محصول الطماطة بمساحة بلغت (20 دونماً) وبنسبة (0,6\%) من مجموع المساحة المزروعة بمحاصيل الخضر الصيفية ، أما محصول اللوبياء فبلغت المساحة المستثمرة بزراعته (50 دونماً) وبنسبة (1,6\%) من مجموع المساحة المزروعة بمحاصيل الخضر الصيفية.

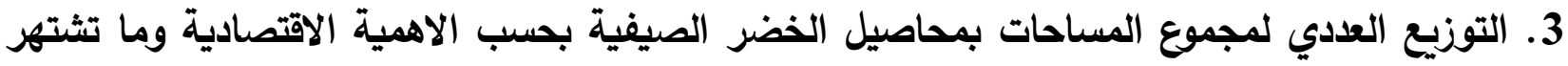
بزراعته منطقة الدراسة وعلى مستوى المقاطعات الزراعية:

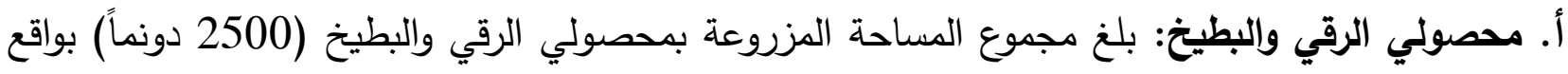

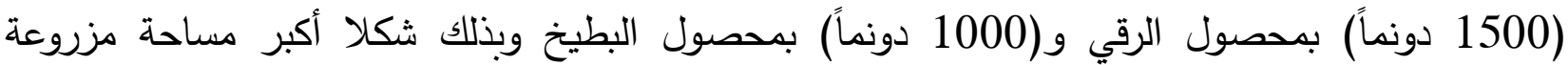

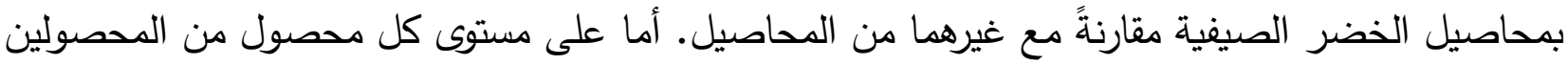
فيتبين من خريطة (7) وبيانات جدول (7) إن أكبر مساحة مزروعة بمحصول الرقي كانت في (مقاطعة 17)

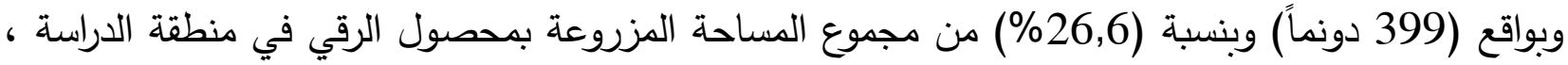
تلتها بالمرتبة الثانية (مقاطعة 18) حيث بلغت ونغية المساحة المزروعة بمحصول الرقي فيها (277 دونماً) وبنسبة (18,5) من مجموع المساحة المزروعة بحصول الرقي في منطقة الدراسة ، لتوافر الموارد المائية بشكل 
جيد في هاتين المقاطعتين ، ومن ثم (مقاطعة 16) بمساحة (224 دونماً) وبنسبة (14,9\%) من المساحة

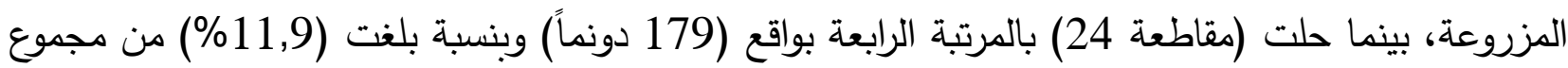
المساحة المزروعة ، أما أصغر مساحة مزروعة بمحصول الرقي في منطقة الدراسة فكانت في (مقاطعة

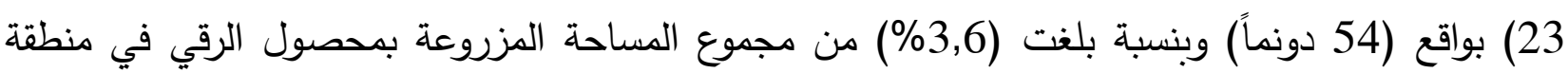
الدراسة ، و (مقاطعة 19) بواقع (73 دونماً) وبنسبة (4,9\%) من مجموع المساحة المزروعة بهذا المحصول بهون في منطقة الدراسة. ويرجع سبب صغر المساحات المزروعة بالرقي في تلك المقاطعات الى قلة المياه وشحتها مما سبب تقلص تلك المساحات ولاسيما المناطق التي تعتمد في ريها على الابار الارتوازية. أما محصول البطيخ فظهرت أكبر مساحة مزروعة بهذا المحصول في (مقاطعة 17) وبنسبة (28,8\%) من مجموع المساحة المزروعة بمحصول البطيخ على مستوى منطقة الدراسة ، تلتها (مقاطعة 18) وبنسبة

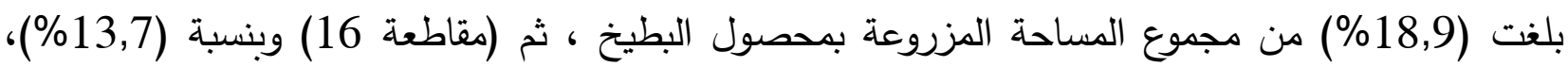
ويعود سبب تصدرها بالمساحات الكبيرة لزراعة محصول البطيخ الى توافر الموارد المائية بثكل جيد وايضاً التربة ذات التصريف الجيد ، بينما كانت أصغر مساحة مزروعة بمحصول البطيخ في المقاطعات (23 و2 2 و19) وبنسبة (3,3\% و5\% و 5,1\%) من المساحة المزروعة بمحصول البطيخ في منطقة الدراسة ، وذلك مزئ

لقلة الموارد المائية فيها. جدول (7) مجموع المساحات المزروعة بمصصولي الرقي والبطيخ بـ (الدونم) ونسبها المئوية حسب المقاطعات الزراعية في منطقة الدراسة عام 2019

\begin{tabular}{|c|c|c|c|c|}
\hline المزموع المساحة المئوية من & مصصاحة & النسبة المئوية من & مصداحة & المقاطعة \\
\hline 5 & 50 & 6,2 & 92 & 2 \\
\hline 6,4 & 64 & 6,3 & 95 & 3 \\
\hline 13,7 & 137 & 14,9 & 224 & 16 \\
\hline 28,8 & 288 & 26,6 & 399 & 17 \\
\hline 18,9 & 189 & 18,5 & 277 & 18 \\
\hline 5,1 & 51 & 4,9 & 73 & 19 \\
\hline
\end{tabular}


مجلة أبحاث ميسان ، المجلد السادس عشر، العدد الثاني والثلاثون ، كانون الأول، السنة 2020

\begin{tabular}{||c||c||c||c||c||}
\hline 6,5 & 65 & 7,1 & 107 & 22 \\
\hline 3,3 & 33 & 3,6 & 54 & 23 \\
\hline 12,3 & 123 & 11,9 & 179 & 24 \\
& & & & \\
\hline 100 & 1000 & 100 & 1500 & \\
\hline \hline
\end{tabular}

المصدر: اعتماداً على مديرية زراعة القادسية، شعبة زراعة عفك، قسم الإنتاج النباتي، 2019، بيانات غير

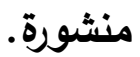

خريطة (7) التوزيع النسبي للمساحات المزروعة بحصولي الرقي والبطيخ في منطقة الدراسة

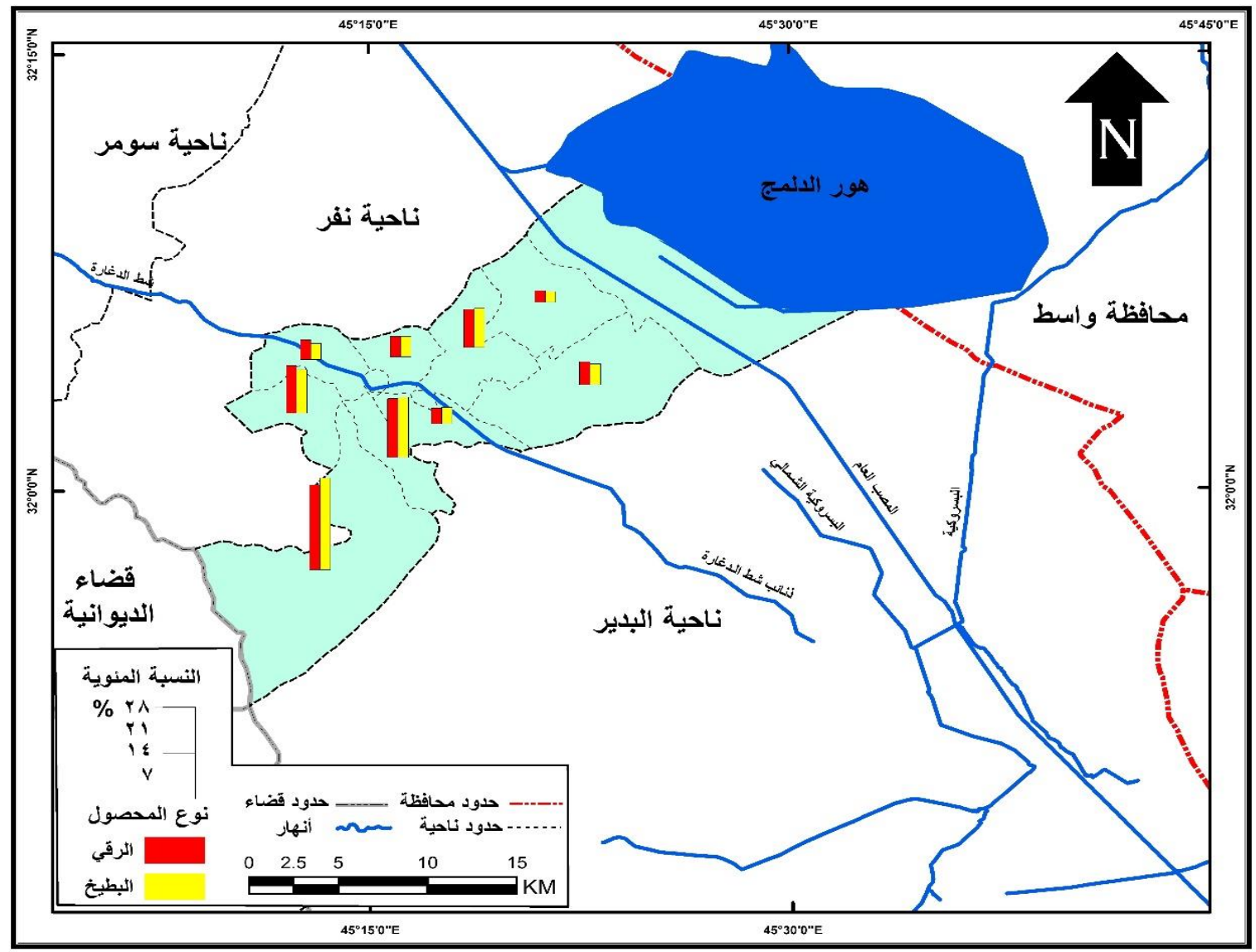

المصدر: اعتماداً على بيانات جدول (7).

ب. محاصيل الباميا والخيار والباذنجان واللوبياء: 
مجلة أبحاث ميسان ، المجلد السادس عشر، العدد الثاني والثلاثون ، كانون الأول، السنة

يتضح من خريطة (8) والجدول (8) أن أكبر المساحات المزروعة بمحاصيل الباميا والخيار والباذنجان واللوبياء ، قد زُرعت بمحصول الباذنجان في مقاطعات القضاء تركزت في المقاطعات (17 و16 و و18 و24)، حيث شكل مجموعها (140 دونماً) وبنسبة (56\%) من مناطعات مجموع المساحة المزروعة بمحصول الباذنجان والبالغة (250 دونماً) في عامة مقاطعات منطقة الدراسة وكانت نسبها المئوية بواقع (24,4)

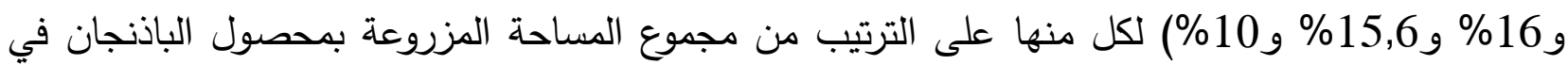

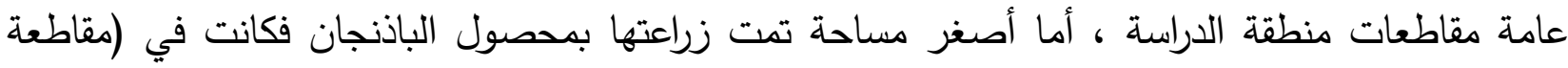
23) وبنسبة بلغت (4,4\%) من مجموع المساحة المزروعة بالمصصول على مستوى منطقة الدراسة و(مقاطعة

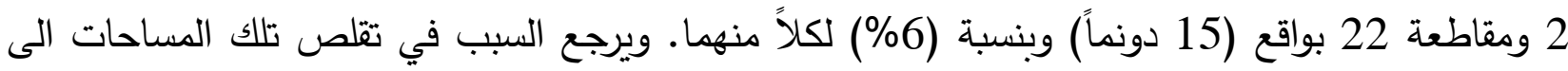

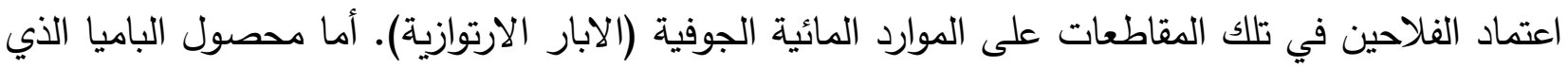
بلغت مساحة زراعته (140 دونماً) في مقاطعات منطقة الدراسة فتركزت النسبة الأكبر من المساحة في أربع

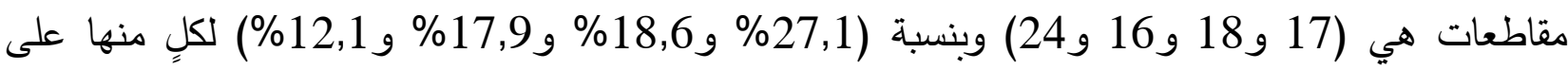

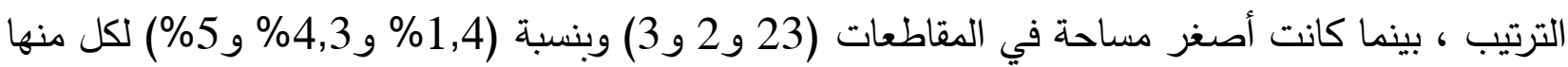
على الترتيب من مجموع المساحة المزروعة بمحصول الباميا. ويرجع السبب في تقلص تلك المساحات الى الى اعتماد الفلاحين في تلك المقاطعات على الموارد المائية الجوفية (الابار الارتوازية). 
جدول (8) مجموع المساحات المزروعة بمحاصيل الباميا والخيار والباذنجان واللوبياء بـ(الدونم) ونسبها المئوية على مستوى المقاطعات الزراعية عام 2019

\begin{tabular}{|c|c|c|c|c|c|c|c|c|}
\hline \% بالمزنوعة الساحة & مصدولة & \% بالمزنوعة المساحة & مصداحة & بالمنروعة & مصنول & بالمصروعة من المساحة & البامياد & رقاطم. \\
\hline 2 & 1 & 6 & 15 & 7 & 6 & 4.3 & 6 & 2 \\
\hline 14 & 7 & 8,8 & 22 & 2,3 & 2 & 5 & 7 & 3 \\
\hline 22 & 11 & 16 & 41 & 17,5 & 15 & 17,9 & 25 & 16 \\
\hline 30 & 15 & 24,4 & 61 & 24,4 & 21 & 27,1 & 38 & 17 \\
\hline 10 & 5 & 15,6 & 39 & 15,1 & 13 & 18,6 & 26 & 18 \\
\hline 0 & 0 & 8,4 & 21 & 5,8 & 5 & 7,9 & 11 & 19 \\
\hline 4 & 2 & 6 & 15 & 5,8 & 5 & 5,7 & 8 & 22 \\
\hline 4 & 2 & 4,4 & 11 & 5,8 & 5 & 1,4 & 2 & 23 \\
\hline 14 & 7 & 10,4 & 26 & 16,3 & 14 & 12,1 & 17 & 24 \\
\hline 100 & 50 & 100 & 250 & 100 & 86 & 100 & 14 & المج \\
\hline
\end{tabular}

المصدر: اعتماداً على مديرية زراعة القادسية، شعبة زراعة عفك، قسم الإنتاج النباتي، 2019، بيانات غير منشورة.

خريطة (8) التوزيع النسبي للمساحات المزروعة بمحاصيل الباميا والخيار والباذنجان واللوبياء في منطقة الدراسة عام 2019 
مجلة أبحاث ميسان ، المجلد السادس عشر، العدد الثاني والثلاثون ، كانون الأول، السنة 2020

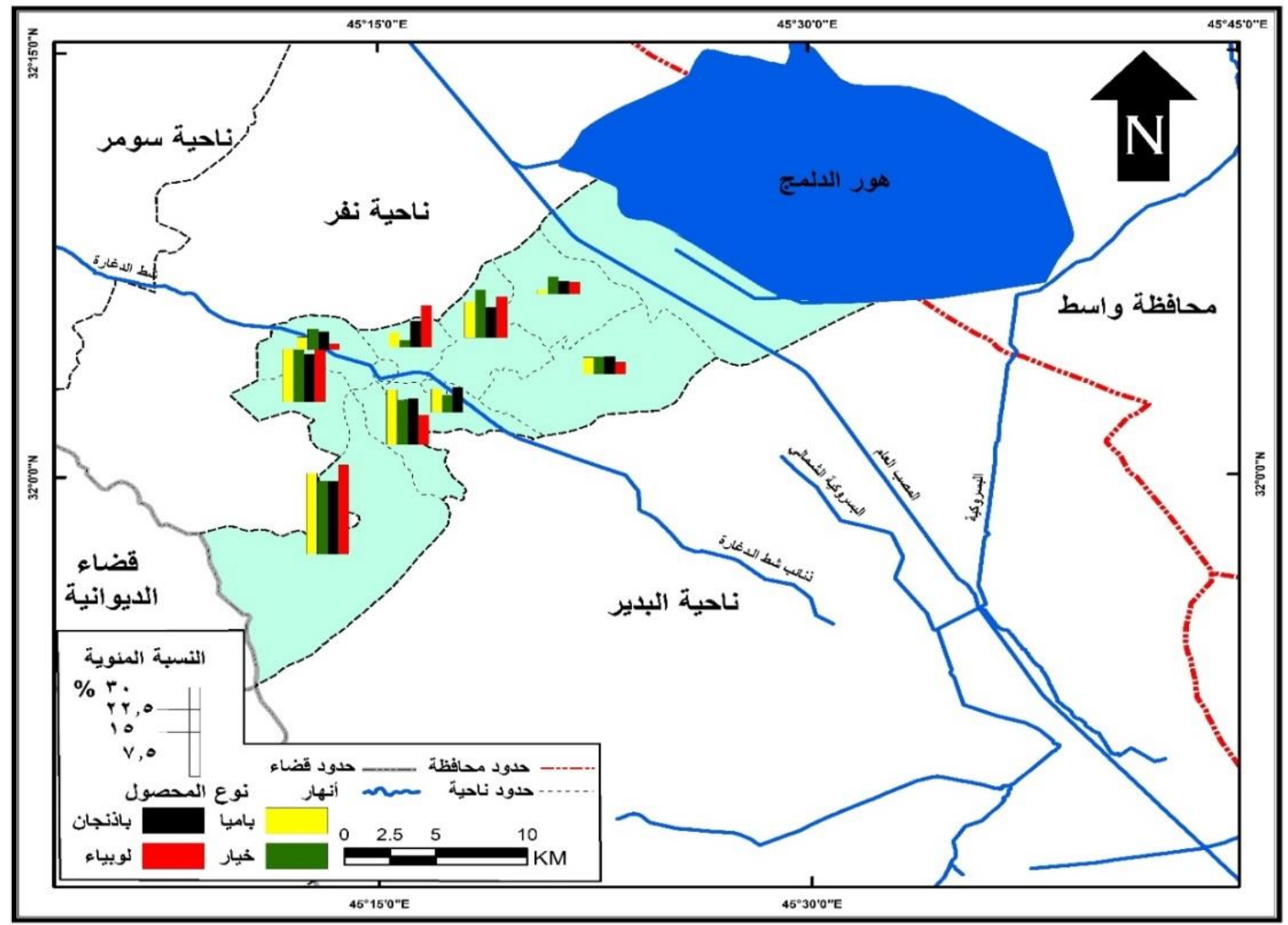

المصدر: اعتماداً على بيانات جدول (8).

أما محصول الخيار الذي بلغت مساحة زراعته (86 دونماً) في عامة الدقاطعات توزعت النسبة الأكبر منها

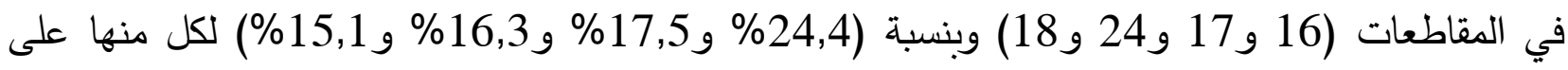

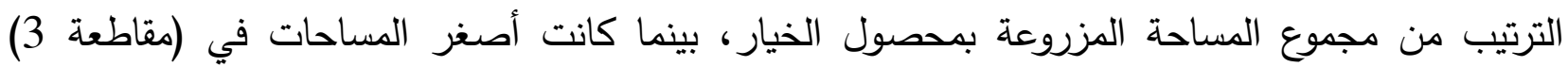
وبنسبة (2,3\%) والمقاطعات (19 و22 و23) وبنسبة (5,8\%) لكل منها من مجموع المساحة المزروعة

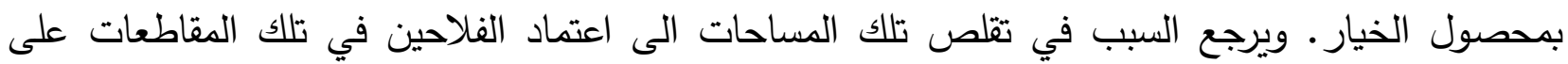
الموارد المائية الجوفية (الابار الارتوازية). أما محصول اللوبياء فبلغت المساحة المزروعة (50 دونماً) فكانت أكبر مساحة في مقاطعتي (17 و16) وبنسبة (30\% و22\%) من مجموع المساحة المزروعة بالمحصول

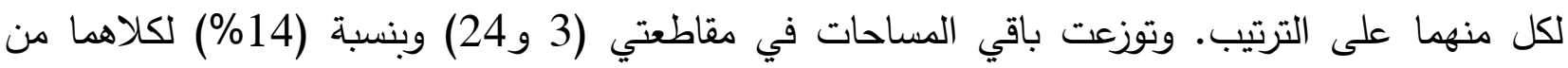

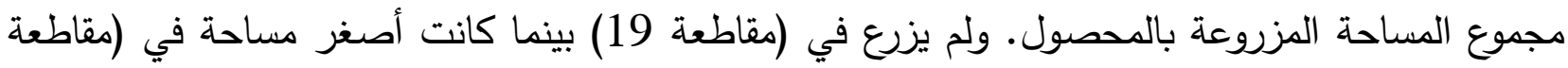

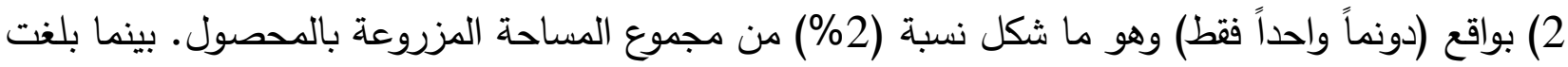

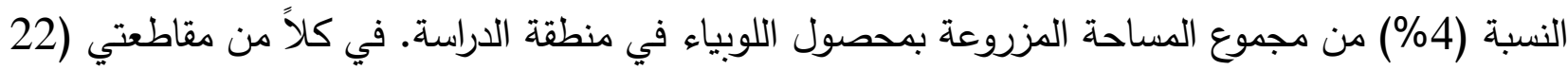
و23). ويرجع السبب في تقلص تلك المساحات الى اعتماد الفلاحين في تلك المقاطعات على الموارد المائية الجوفية (الابار الارتوازية). ج. محاصيل الطماطة والفلفل والثجر والخضر الورتئل 
يتبين من الخريطة (9) وبيانات الجدول (9) إن مجموع المساحة المزروعة بالخضر الورقية والبالغة (30

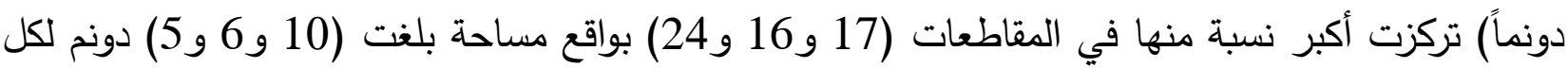
منها على الترتيب ، وبنسب بلغت (33,3\% و2\% و و16,7\%) من مجموع المساحة المزروعة بالخضر

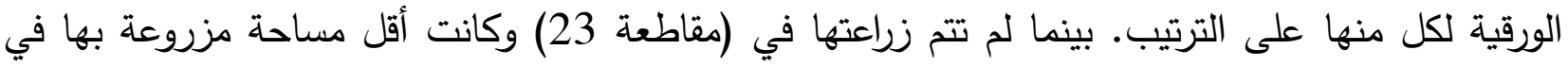

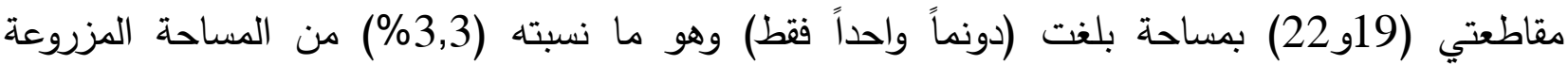

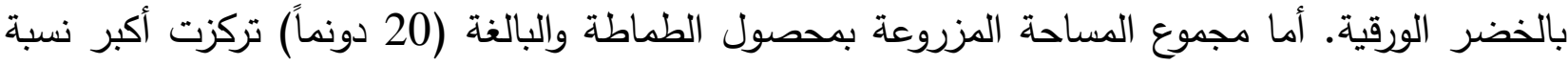
في المقاطعات (17 و16 و3) وبنسبة (35\% و25\% و10\%) من مجموع المساحة المزروعة لكلٍ منها

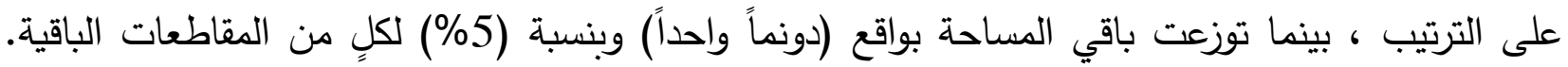
وبالنسبة لدحصولي الفلفل والثجر اللذان بلغت المساحة المزروعة لكل منهما (10 دونماً) في منطقة الدراسة

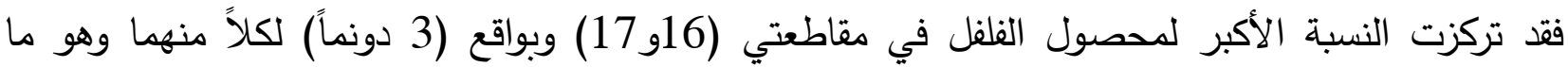
نسبته(30\%) من مجموع المساحة المزروعة بمحصول الفلفل ، ولم تتم زراعته في المقاطعات (2 و3 و و23)، وكانت أقل مساحة مزروعة في المقاطعات (18 و19 و22) وبنسبة (10\%) من مجموع المساحة المزروعة بالمحصول على مستوى المقاطعات في كلٍ منها. ويرجع السبب في تقلص تلك المساحات الى اعتماد الفلاحين في تلك المقاطعات على الموارد المائية الجوفية (الابار الارتوازية). جدول (9) مجموع المساحات المزروعة بمحاصيل الطماطة والفلفل والثجر والخضر الورقية بـ(الدونم) ونسبها المئوية على مستوى المقاطعات الزراعية عام 2019

\begin{tabular}{|c|c|c|c|c|c|c|c|c|}
\hline المزروعة بالمصصود & وقضية & 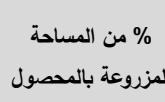 & الثجر & \% الثنروعة بالمصادول & فلفل & لمزرعة من المسادون & الططاطة & رقاطعة \\
\hline 6,7 & 2 & 10 & 1 & 0 & $\mathbf{0}$ & 5 & 1 & 2 \\
\hline 6.7 & 2 & 0 & 0 & 0 & 0 & 10 & 2 & 3 \\
\hline 20 & 6 & 10 & 1 & 30 & 3 & 25 & 5 & 16 \\
\hline 33,3 & 1 & 30 & 3 & 30 & 3 & 35 & 7 & 17 \\
\hline 10 & 3 & 10 & 1 & 10 & 1 & 5 & 1 & 18 \\
\hline $\mathbf{3}, \mathbf{3}$ & 1 & 20 & 2 & 10 & 1 & 5 & 1 & 19 \\
\hline 3,3 & 1 & 10 & 1 & 10 & 1 & 5 & 1 & 22 \\
\hline 0 & 0 & 0 & $\mathbf{0}$ & 0 & $\mathbf{0}$ & 5 & 1 & 23 \\
\hline 16,7 & 5 & 10 & 1 & 10 & 1 & 5 & 1 & 24 \\
\hline
\end{tabular}


مجلة أبحاث ميسان ، المجلد السادس عشر، العدد الثاني والثلاثون ، كانون الأول، السنة 2020

\begin{tabular}{|c|c|c|c|c|c|c|c|c|}
\hline 100 & 3 & 100 & 1 & 100 & 1 & 100 & 20 & المج \\
\hline
\end{tabular}

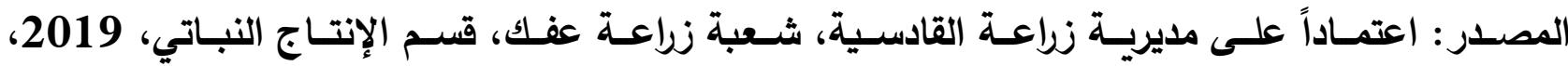
بيانات غير منشورة.

\section{خريطة (9)}

التوزيع النسبي للمساحات المزروعة بمحاصيل الطماطة والفلفل والثجر والخضر الورقية عام 2019

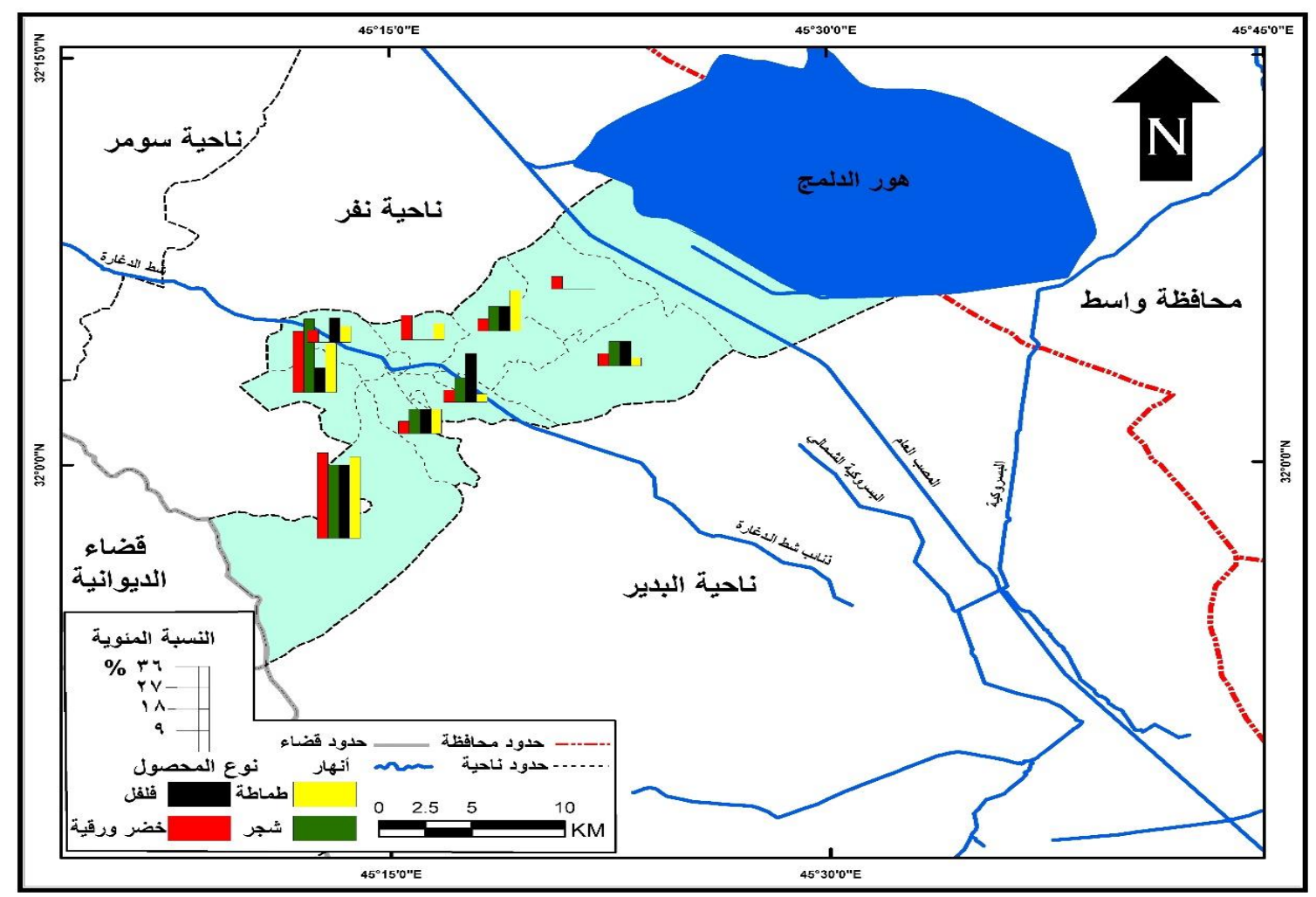

المصدر : اعتماداً على بيانات جدول (9).

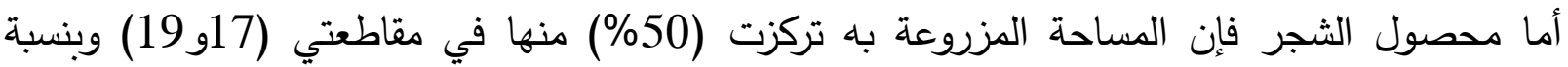
(30\% و20\%) لكل منهما على الترتيب، في حين لم تتم زراعته في مقاطعتي (3 و 23)، وكانت أصغر

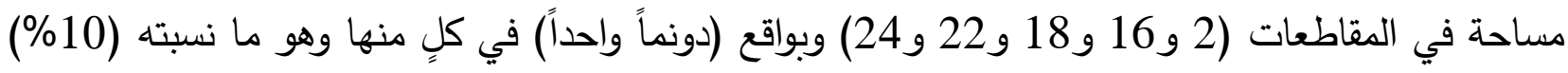
من مجموع المساحة المزروعة بالمحصول لكل مقاطعة.

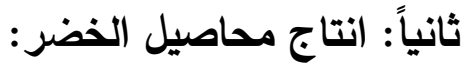
يتبين من الجدول (10) إن أعلى كمية إنتاج كانت في محصول الرقي بواقع (8949 طن) وذلك لكبر

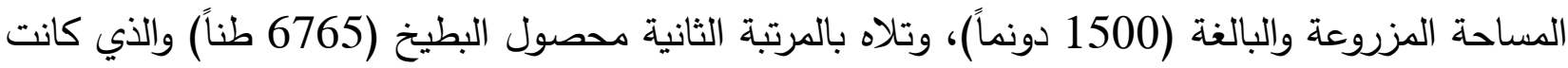

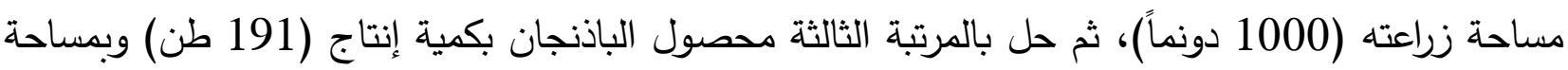


بلغت (250 دونماً)، ثم محصول الباميا بكمية إنتاج (73,98 طن) ومساحة بلغت (140 دونماً)، في ما

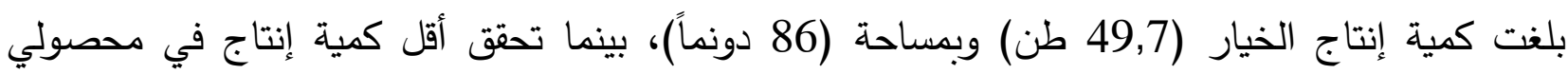
اللوبياء والطماطة حيث بلغت لمحصول اللوبياء (16,1 طن) وبمساحة (50 دونماً)، وبلغت كمية إنتاج

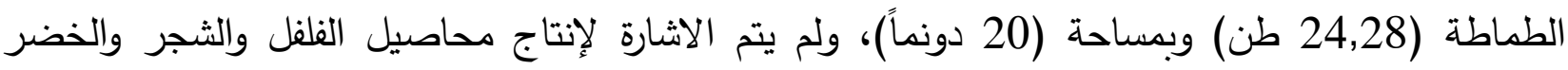
الورقية لعدم توافر البيانات الخاصة بإنتاجها في الثعب الزراعية.

جدول (10) كميات إنتاج محاصيل الخضر الصيفية في قضاء عفك عام 2019

\begin{tabular}{|c|c|c|c|}
\hline الإنتاج (طن) & المحصول & الإنتاج (طن) & المحصول \\
\hline 191 & باذنجان & 8949 & رقى \\
\hline 16,1 & لوبياء & 6765 & بطيخ \\
\hline \multirow{2}{*}{24,28} & \multirow{2}{*}{ طماطة } & 73,98 & باميا \\
\hline & & 49,7 & خيار \\
\hline
\end{tabular}

المصدر: اعتماداً على مديرية زراعة القادية، شعبة زراعة عفك، قسم الإنتاج النباتي، 2019، بيانات غير منشورة.

شكل (10) كميات إنتاج محاصيل الخضر الصيفية بـ (الطن) في منطقة الدراسة عام 2019

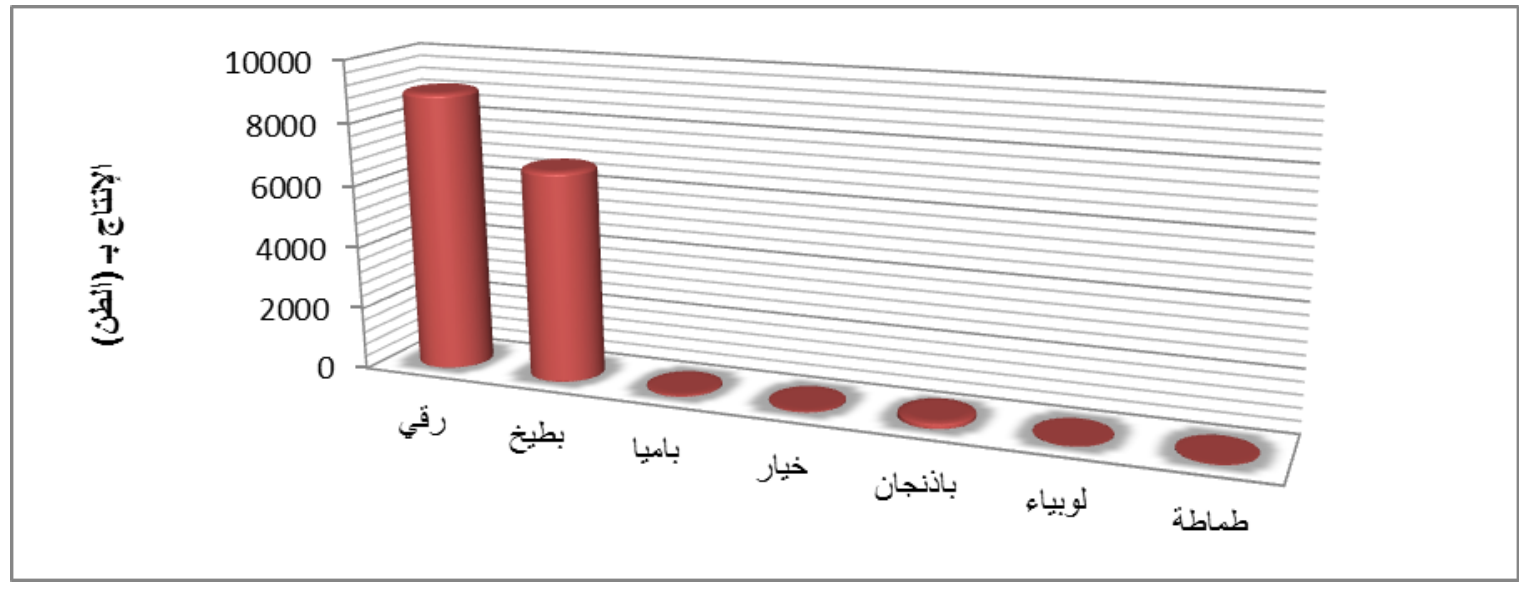

المصدر: اعتماداً على بيانات جدول (10).

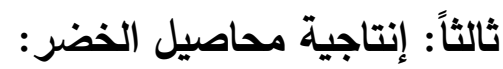

يتبين من الجدول (11) إن أكبر غلة إنتاجية كانت في محصول البطيخ حيث بلغت (6765 كغم/دونم)، وحل محصول الرقي بالمرتبة الثانية بعده من حيث الإنتاجية وبواقع (11ان (5966 كغم/دونم)، وحل بالمرتبة الثالثة

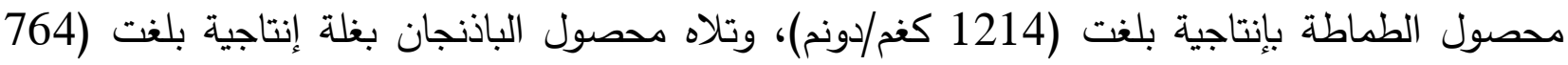


مجلة أبحاث ميسان ، المجلد السادس عشر، العدد الثاني والثلاثون ، كانون الأول، السنة

كغم/دونم)، فيما كانت أقل غلة إنتاجية في المساحات المزروعة بمحصول اللوبياء (322 كغم/دونماً) والباميا

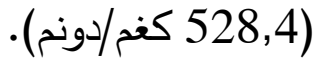

جدول (11) إنتاجية محاصيل الخضر الصيفية في قضاء عفك عام 2019

\begin{tabular}{|c|c|c|c|}
\hline الإنتاجية كفم| & |المحصول & الإنتاجية كفم| & المحصول \\
\hline 764 & |باذنجان & 5966 & رقي \\
\hline 322 & لوبياء & 6765 & بطيخ \\
\hline \multirow{2}{*}{1214} & \multirow{2}{*}{ | الطماطة } & 528,4 & باميا \\
\hline & & 577,9 & خيار \\
\hline
\end{tabular}

المصدر: اعتماداً على مديرية زراعة القادسية، شعبة زراعة عفك، قسم الإنتاج النباتي، 2019، بيانات غير منشورة.

شكل (11) إنتاجية محاصيل الخضر الصيفية في منطقة الدراسة

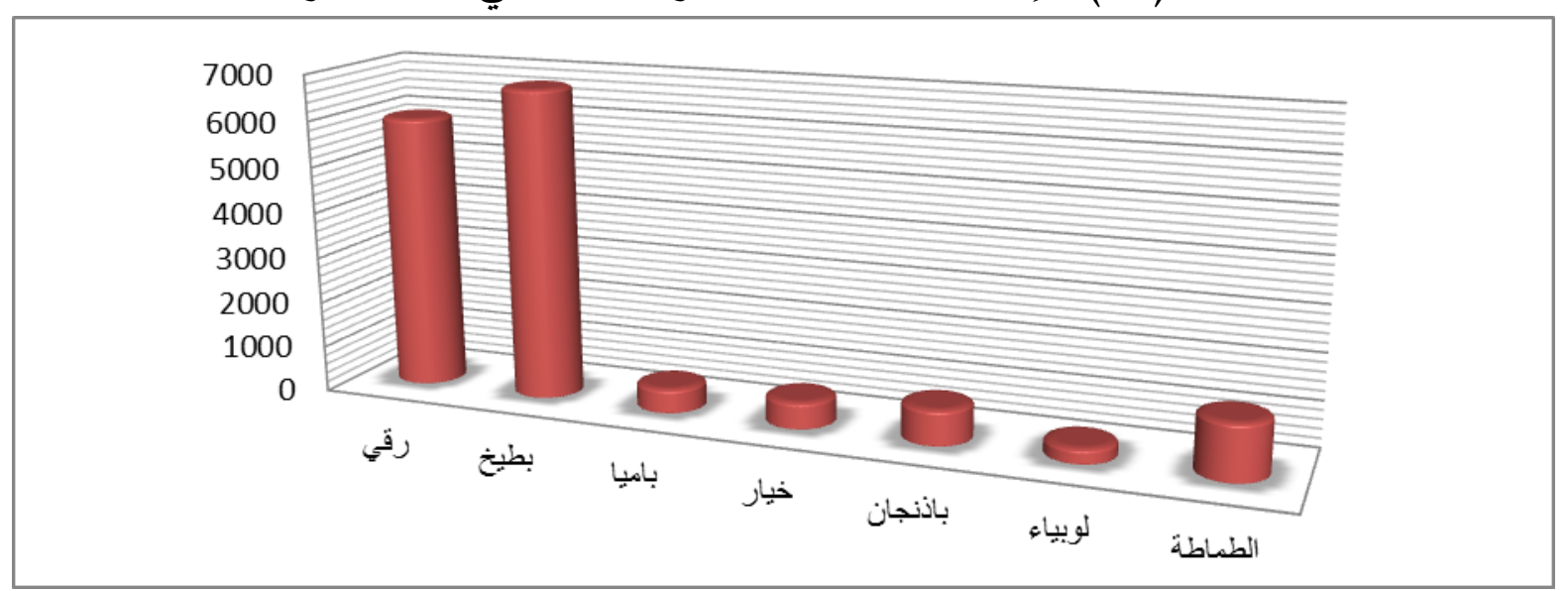

المصدر: اعتماداً على بيانات جدول (11)

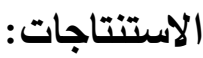

1. استتتج البحث إن النسبة (72,4\%) من المساحة المزروعة بمحاصيل الخضر الصيفية تركزت في أربع مقاطعات (17 و18 و16 و24) وبنسبة (27,3\% و17,9\% و 15,1\% و 12,1\%) لكلٍ منها على الترتيب ، بينما لم تزرع في مقاطعتي (26 و 21) الأولى لثحة المياه والثانية لصغر مساحتها وتخصصها ببساتين 
مجلة أبحاث ميسان ، المجلد السادس عشر، العدد الثاني والثلاثون ، كانون الأول، السنة

النخيل. وكانت أقل مساحة في مقاطعتي (23 و19) وبنسبة (3,5\% و5,4\%) لكلٍ منهما على الترتيب من مجموع المساحة المزروعة بمحاصيل الخضر الصيفية. 2. بلغ مجموع المساحة المزروعة بمحاصيل الخضر الصيفية في منطقة الدراسة (3096 دونماً) وكانت أكبر مساحة لدحصولي الرقي والبطيخ وبنسبة (48,5\% و32,3\%) لكل منهما على الترتيب. وإن المساحات المزروعة بمحصولي الفلفل والثجر هي أصغر نسبة والبالغة (0,3\%).

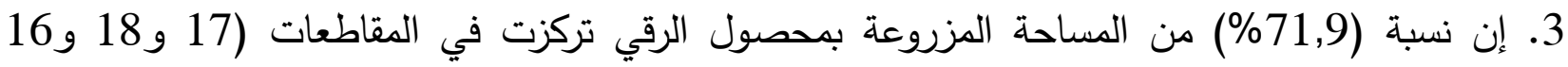

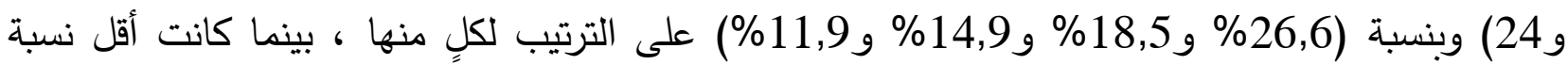

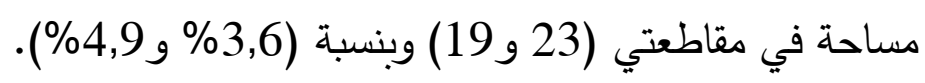

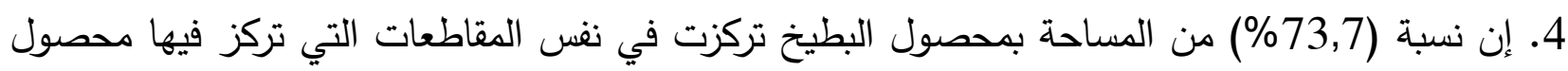

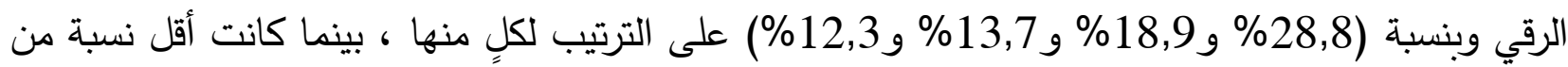

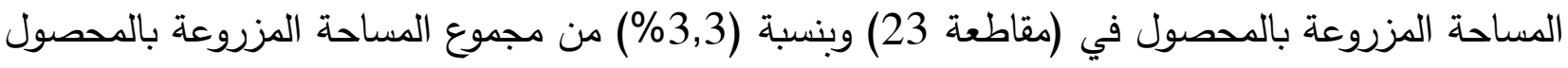
في منطقة الدراسة. وإن نسبة (66,4\%) من المساحة المزروعة بمحصول الباذنجان تركزت في المقاطعات الدذكورة أعلاه وبنسبة (24,4\% 15,6\% و16\% و و 10,4\%) على الترتيب لكلٍ منها ، بينما كانت أقل نسبة من المساحة في (مقاطعة 23) وبنسبة (4,4\%) ومقاطعتي (2 و22) وبنسبة (6\%). وإن أعلى نسبة من ون

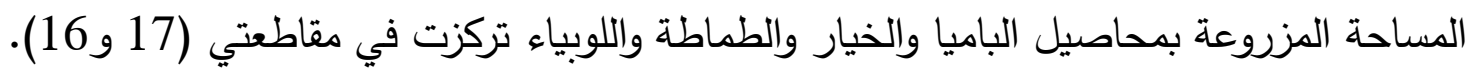
5. إن أكبر كمية إنتاج لمحاصيل الخضر تحقت في محصول الرقي (8949 طن) ثم البطيخ (6765 الخيل طن)، بينما تحقق أقل كمية إنتاج في محصول اللوبياء (16,1 طن) ، ومحصول الطماطة (24,28 طن)

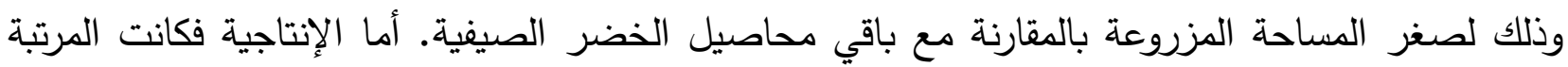

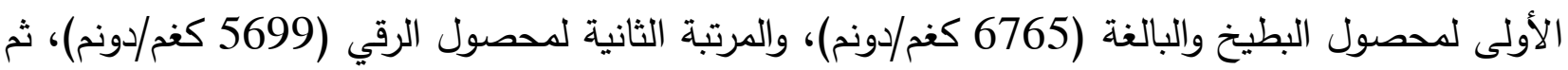

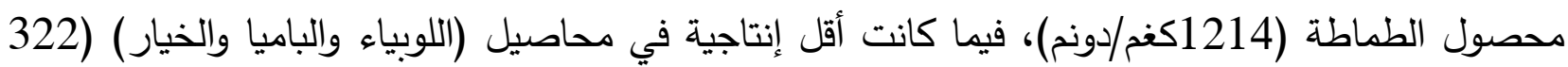
و528,4 و577,9 5 كغر/:دونم.

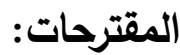

1. توفير الدعم الحكومي المتمثل بتوفير القروض الزراعية للمزارعين لتشجيعهم في زراعة محصول الخضر

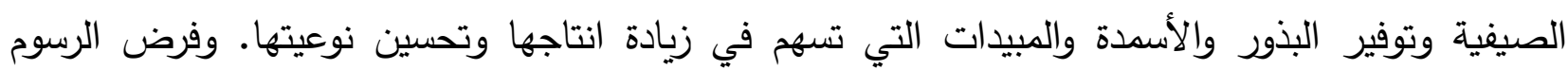
والتعريفات الكمركية على المنتجات الزراعية المستوردة لتقليل منافتها للمنتج المحلي. 2. تعاني منطقة الدراسة من قلة المساحات المزروعة ببعض محاصيل الخضر الصيفية ومنها الطماطة

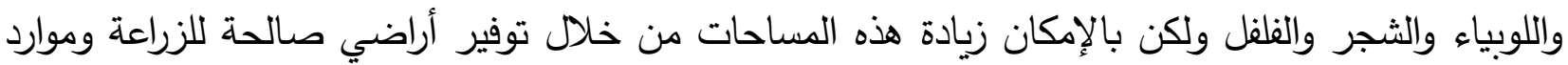

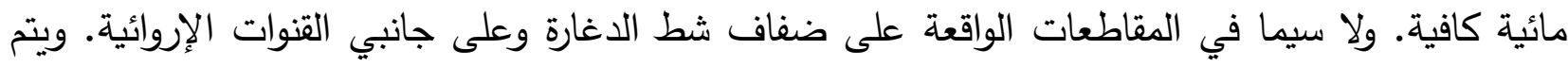

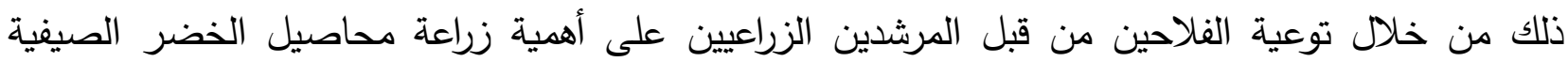


مجلة أبحاث ميسان ، المجلد السادس عشر، العدد الثاني والثلاثون ، كانون الأول، السنة

وتخصص المزارعين في محاصيل معينة منها بما يسهم في اكتساب الخبرة وزيادة جودة المنتج المحلي

$$
\text { هوامش البحث: }
$$

(1) محمد خضير كلف الحويس، التحليل المكاني للإنتاج الزراعي(النباتي) وعلاقته بالموارد المائية في

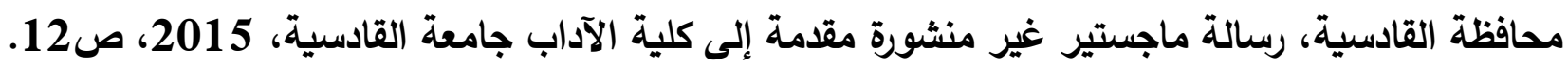

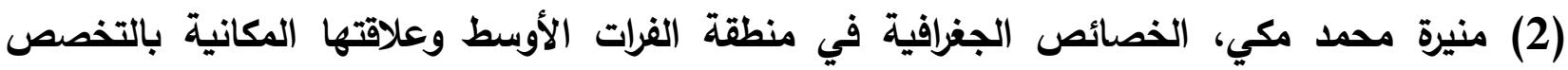

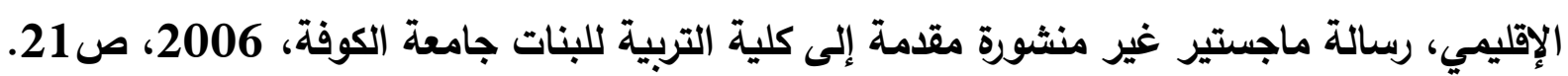

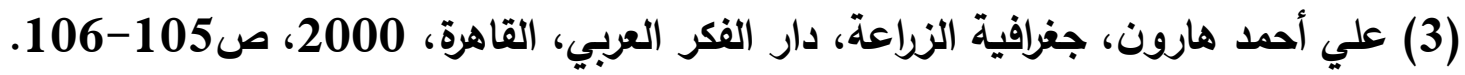

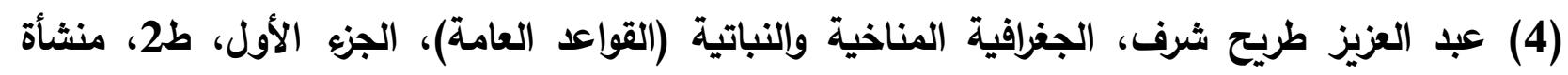

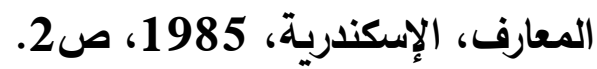
(5) علاء داود مختار وحسين مجاهد مسعود، أساسيات الجغرافية الطبيعية، دار زهران للنشر والتوزيع،

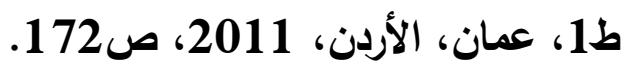
(6) خلف حسين الأليمي، الجيومورفولوجيا التطبيقية (علم أشكال سطح الأرض التطبيقي)، الطبعة العربية

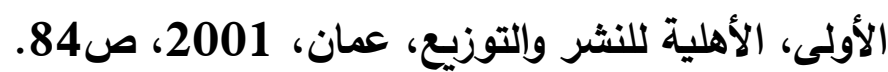
(7) خلود علي حسين العبيدي، التحليل المكاني لاستعمالات الأرض الزراعية في قضاء عفك، الأهيه، رسالة

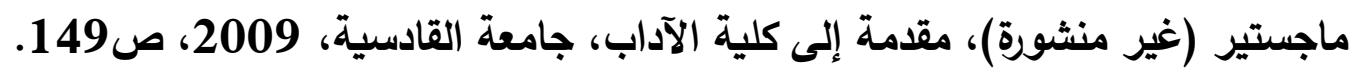

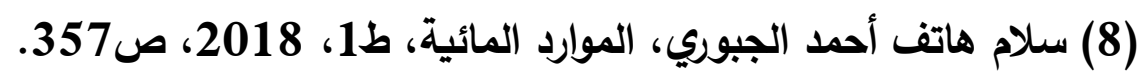
(9) رباب حسن كاظم الجياشي، تحليل جغرافي لمعوقات التنمية الزراعية في محافظة المثنى، رسالة

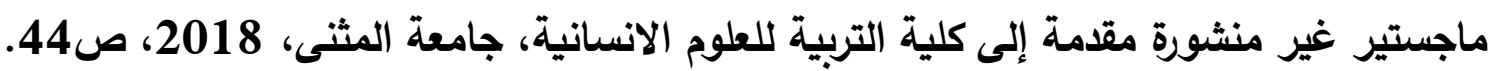

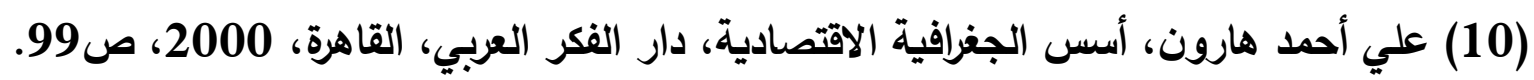

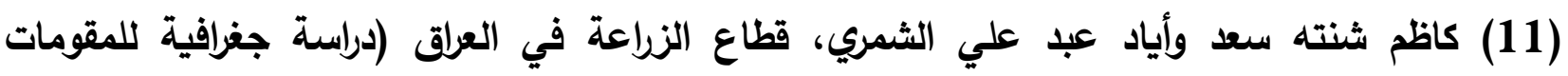

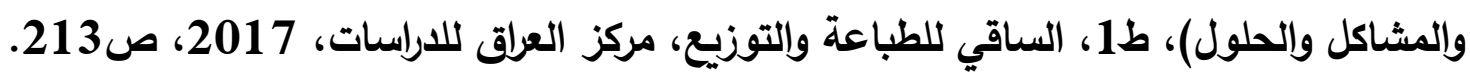

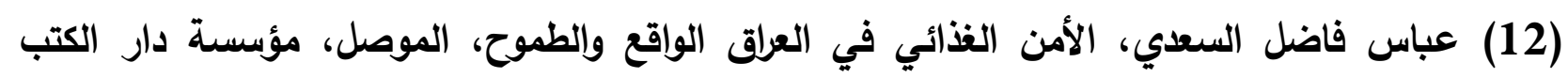

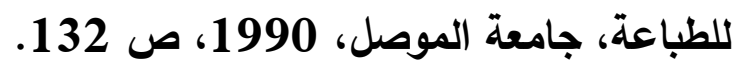
(13) حسين ذياب محمد وعباس حمزة علي، تقييم التنمية الزراعية في ريف مركز قضاء عفك في ظل

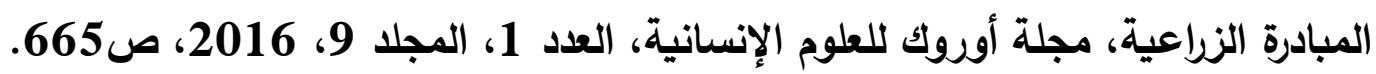
(14) عباس حمزة علي الثمري، التخطيط الاستراتيجي للتنمية الريفية في قضاء عفك، أطروحة دكتوراه

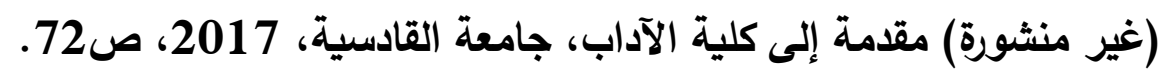


(15) عبد الوهاب مطر الدهري، الاقتصاد الزراعي، دار الكتب للطباعة والنشر، الموصل، 1986، ص

(16) كاظم شنته سعد وأياد عبد علي الثمري، مصدر سابق، ص226.

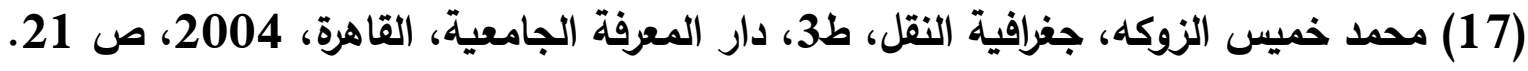

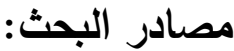
1. جمهورية العرلق، وزارة البلديات والأثثال العامة، العديرية العامة للتخطيط العمراني، مديرية التخطيط

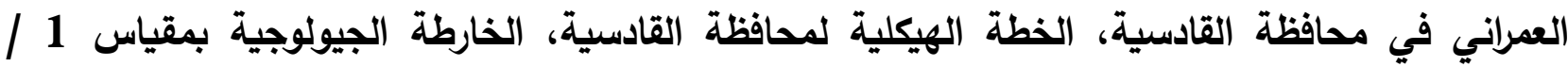
500000، عام 2012. 2. جمهورية العرق، وزارة الزراعة، مديرية زراعة محافظة القادية، خارطة مقاطعات القادسية بمقياس1/2000/ 500000 5000 2012 3. حسين ذياب محمد وعباس حمزة علي، تقييم التنمية الزراعية في ريف مركز قضاء عفك في ظل المبادرة الزراعية، مجلة أوروك للعلوم الإنسانية، العدد 1، المجلد 9، 2016. 4. خلف حسين الاليمي، الجيومورفولوجيا التطبيقية(علم أثكال سطح الأرض التطبيقي)، ط1، مكتبة الأهلية ،

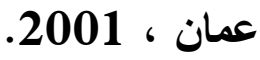

5. خلود علي حسين العبيدي، التحليل المكاني لاستعمالات الأرض الزراعية في قضاء عفك، رسالة ماجستير

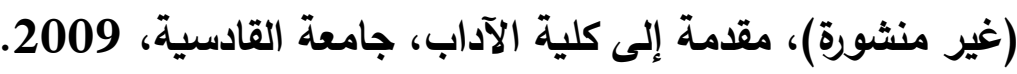

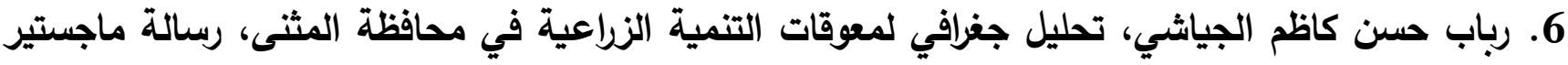

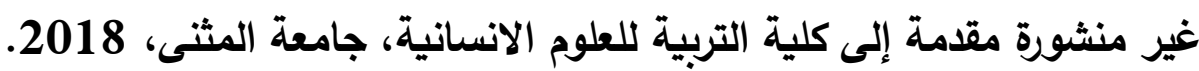
7. سلام هاتف أحمد الجبوري، الموارد المائية، ط1، كفئ،

8. عباس حمزة علي الشمري، التخطيط الاستراتيجي للتنمية الريفية في قضاء عفك، أطروحة دكتوراه (غير الغوائ منشورة) مقدمة إلى كلية الآداب، جامعة القادية، 2017.

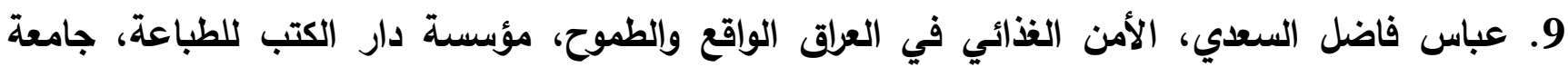
الموصل، 1990. 10. عبد العزيز طريح شرف، الجغرافية المناخية وإلنباتية (القواعد العامة)، الجزء الأول، ط2، منشأة المعارف، الإسكندرية، 1985. 198 11.عبد الوهاب مطر الدهري، الاقتصاد الزراعي، دار الكتب للطباعة والنشر، الموصل، 1986.

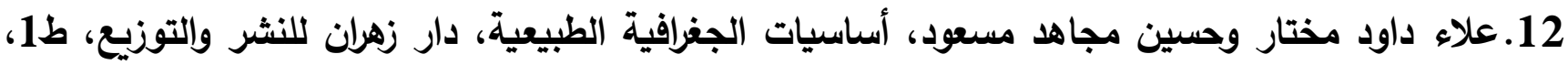
عمان، الأردن، 2011. 13.علي أحمد هارون، أسس الجغرافية الاقتصادية، دار الفكر العربي، القاهرة، 2011. 


$$
\text { 14.علي أحمد هارون، جغرافية الزراعة، دار الفكر العربي، القاهرة، } 2000 .
$$

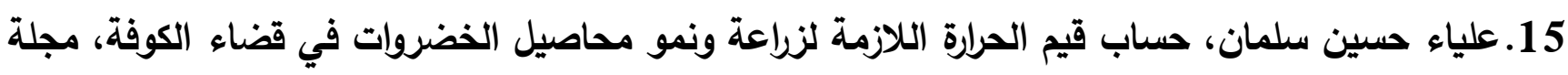
معين، جامعة الكفيل، العدد 4، 2015. 16.كاظم شنته سعد وأياد عبد علي الثمري، قطاع الزراعة في العراق (دراسة جغرافية للمقومات والمشاكل

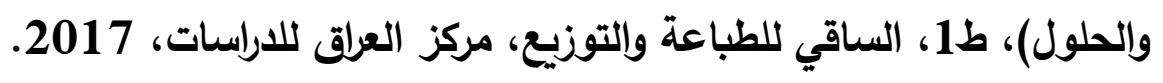

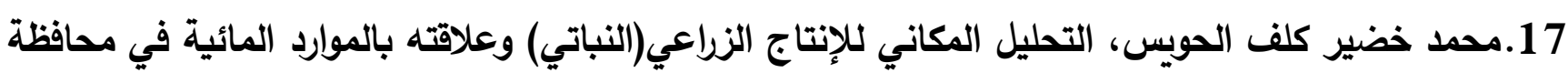
القادسية، رسالة ماجستير غير منثورة مقدمة إلى كلية الآداب جامعة القادسية،

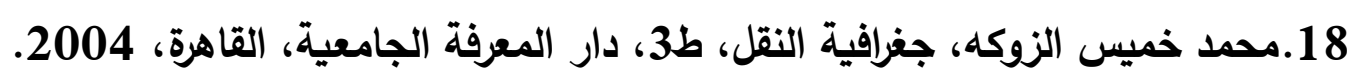

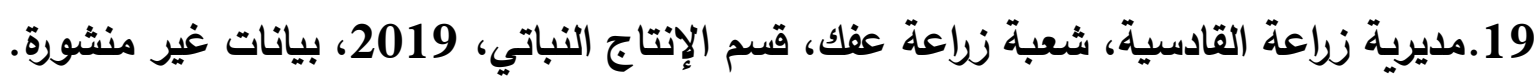

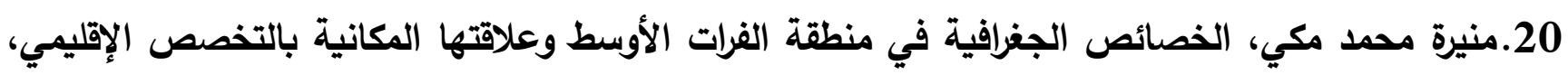
رسالة ماجستير غير منشورة مقدمة إلى كلية التربية للبنات جامعة الكوفة، 2006.

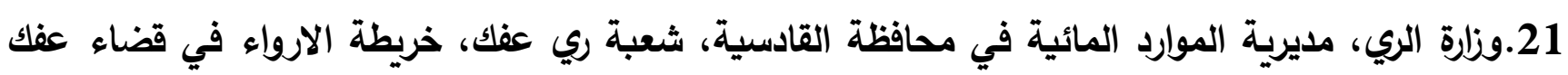
عام 2018.

22.وزارة الموارد المائية، المديرية العامة للمساحة، قسم انتاج الخرائط الرقمية M.P.D، خارطة محافظة

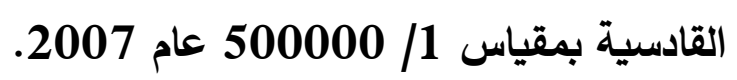

23.وفاء موحان عجيل، أثر المناخ في إنتاج محاصيل الخضر الصيفية في محافظة القادسية، رسالة ماجستير

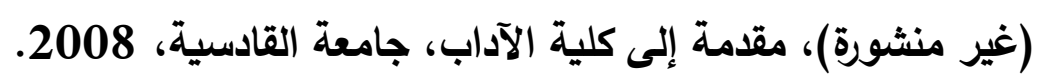

